ANUARIO DE ESTUdios MEDIEVALES

44/2, julio-diciembre de 2014, pp. 845-884

ISSN 0066-5061

doi:10.3989/aem.2014.44.2.06

\title{
CIUDADES Y PODER POLÍTICO EN AL-ANDALUS. UNA HIPÓTESIS SOBRE EL ORIGEN DE LAS REVUELTAS URBANAS EN MURCIA EN EL SIGLO XIII
}

\author{
CITIES AND POLITIC POWER IN AL-ANDALUS. \\ A HYPOTHESIS ABOUT THE ORIGIN OF THE URBAN RIOTS \\ IN MURCIA IN THE XIIIth CENTURY
}

Resumen: Durante el siglo XIII se produjo una serie de revueltas urbanas en al-Andalus que ocasionó la retirada del Imperio almohade y la formación de las terceras taifas, inicialmente encabezadas por Muhammad b. Yūsuf b. Hūd al-Mutawakkil. La incapacidad de este emir para mantener unido el estado que había creado y las continuas insurrecciones fuera y dentro de Murcia ha llevado a historiadores y filólogos a indagar sobre la naturaleza del poder político en este periodo. Este artículo estudia cada una de estas interpretaciones y, a partir del análisis de algunos aspectos socio-económicos de Murcia, ciudad representativa en al-Andalus y capital del movimiento hūdí durante la primera mitad del siglo XIII, presenta una propuesta sobre la naturaleza de su poder.

Palabras clave: siglo XIII; Ibn Hūd; alAndalus; Murcia; sociedad; revueltas; ciudades; urbanismo; viviendas; campo; propiedad; producción.

\section{ANTONIO VicEnTE FREy SÁNCHEZ \\ Murcia}

Abstract: Throughout the 13th century a succession of urban revolts took place in al-Andalus, which caused the withdrawal of the Almohad Empire and the establishment of the third taifas, initially led by Muhammad b. Yūsuf b. Hūd alMutawakkil. The inability of this emir to hold together this newly-built state, and the continuous insurrections inside and outside of Murcia have led historians to investigate the nature of political power during this period. This article examines each one of these proposals and, on the basis of an analysis of some socio-economic aspects relating to Murcia (being a representative city of al-Andalus and capital of the hūdí movement during the first half of the thirteenth century), proposes a hypothesis on the nature of its power.

Keywords: 13th century; Ibn Hūd; alAndalus; Murcia; society; revolts; cities; town planning; houses; field; society; property; production.

\section{SUMARIO}

1. Introducción. Crisis política en al-Andalus. La importancia de las ciudades.2. Génesis de las revueltas urbanas. Soluciones propuestas.-3. Una hipótesis para el estudio de las revueltas urbanas.- 3.1. Hambrunas, cabalgadas y desplazamientos de población.- 3.2. La fragmentación del parcelario y su crecimiento en altura.- 3.3. La parcelación y concentración de la propiedad de la tierra en la huerta.- 4. Síntesis y 
conclusiones: una hipótesis sobre la sociedad y poder político en las ciudades de alAndalus en el siglo XIII a través del ejemplo de Murcia.- 5. Bibliografía citada.

\section{INTRODUCCIÓN. CRISIS POLÍTICA EN AL-ANDALUS. LA IMPORTANCIA DE LAS CIUDADES}

El testimonio de las fuentes escritas árabes y castellanas medievales hace referencia a un conjunto de revueltas urbanas que sacudieron al-Andalus entre los años 1228 y 1248. Un confuso movimiento de emancipación que comenzó en Murcia trastocó, a la altura del último año citado, todo el paisaje político andalusí. La inicial sublevación contra el poder almohade en la península ibérica y las posteriores revueltas urbanas supusieron uno de los últimos fenómenos sociopolíticos de al-Andalus antes de su desaparición. Tanta es la importancia de aquel hecho que numerosos historiadores han procurado definir su contexto histórico ${ }^{1}$. En todos los casos y dada su trascendencia, se ha prestado atención al personaje que llevó a cabo la sublevación inicial -Muhammad b. Yūsuf b. Hūd al-Mutawakkil- y a aquellos que parecieron actuar en connivencia con éste.

A la hora de estudiar aquel fenómeno, salvo casos muy excepcionales que han tratado de delimitar el papel representado por los habitantes de las ciudades, se ha prestado moderada atención a los aspectos materiales, más aún cuando se ha comprobado - a través de la arqueología y diversas fuentes escritas como los repartimientos de Murcia- el constante y estrecho vínculo entre ambos. Sin dejar de lado las propuestas hasta ahora defendidas, un análisis del papel jugado por el conjunto del campo, de las huertas y sus pobladores así como de las ciudades y sus habitantes en las numerosas sublevaciones andalusíes iniciadas en 1228 puede contribuir a demostrar el grado de implicación e interrelación de los diferentes estamentos de la sociedad andalusí en toda aquella serie de movimientos. Los mismos que después, durante el gobierno de Ibn Hūd al-Mutawakkil, se mantuvieron más o menos latentes y que, tras la muerte del carismático emir, precipitaron la desintegración de al-Andalus y la consiguiente conquista de sus ciudades. La inserción de las condiciones materiales del campo y de las ciudades en el discurso sobre las agitaciones de la primera mitad del siglo XIII permite enriquecer la perspectiva y valorar mejor la decisiva importancia de aquellos acontecimientos, caracterizados fundamentalmente por la ausencia de un poder político fuerte y por la crisis social.

\footnotetext{
${ }^{1}$ Por citar los más representativos: I. de las Cagigas, Los mudéjares; P. Guichard, Les musulmans de Valence et la reconquête y, sobre todo, E. Molina, El Levante y Almería, pp. 55-61 e idem, De nuevo sobre el reconocimiento público, pp. 793-812.
} 
De hecho, fue la ausencia de un poder político que aglutinase todo al-Andalus el factor decisivo que precipitó su destrucción; es verdad que la derrota de Las Navas de Tolosa no había destruido al Imperio almohade, pero sí es cierto que contribuyó a sembrar el desconcierto tanto entre los propios almohades como entre los andalusíes, dando como resultado una reacción institucional en cadena $^{2}$. Los ejemplos más palpables fueron las insurrecciones ocurridas tras la muerte del califa Yūsuf II (enero de 1224), protagonizadas por miembros de su propia familia, que alegaban derechos dinásticos ${ }^{3}$. Cuando se observan bien estas insurrecciones, que consistieron en ruidosos y fugaces pronunciamientos, resulta que tuvieron una misma estructura y fin; estructura y fin que no dudaron en reproducir después los propios andalusíes. Así ocurrió con el alzamiento de Ibn Hūd (1228, al-Ṣujūr), de Zayyān b. Mardanīš (1229, Onda) o de Ibn al-Ahmar b. Nașr (1232, Arjona); todos ellos recibieron el reconocimiento de sus habitantes -la denominada bay $^{c} a-$ y la consiguiente legitimidad exterior ${ }^{4}$.

El levantamiento de 1228 no habría tenido mayor importancia de no haber sido seguido por otros que culminaron con la sublevación nazarí de 1232. Y el hecho de que otras resistencias urbanas continuaran hasta 1247 en las inmediaciones de Murcia y hasta 1248 en la actual Andalucía, negándose las más de las veces a acatar una autoridad suprema incluso a costa de su propia supervivencia, invita al historiador a indagar sobre su naturaleza.

\section{GÉNESIS DE LAS REVUELTAS URBANAS. INTERPRETACIONES PROPUESTAS}

$\mathrm{Si}$, como acabo de exponer más arriba, los gobernadores locales almohades fueron capaces de poner las guarniciones a su favor y de lanzarse a la carrera por el califato, la cuestión es saber cómo lo consiguieron los andalusíes, carentes de ejército regular. La lectura del Bayān al-Mugrib de Ibn 'Id̄ārī y del Kitāb al-Rawd de al-Himyarī permite conocer, más o menos y con detalles significativos, lo que ocurrió en junio de 1228. En esa fecha, Muhammad b. Yūsuf b. Hūd, que por lo menos desde 1217 era reconocido comandante del ejército regular, al ser menospreciado por el sayyid de Murcia Abūl-Amān, abandonó su posición y se adhirió a una partida de bandoleros capitaneados por un qā'id llamado al-Guštī, con los que se dedicó a saquear los territorios fronterizos bajo control castellano ${ }^{5}$. Dada su experiencia militar

\footnotetext{
${ }^{2}$ La cuestión fue reflejada por A. Huici en Historia política, pp. 382-383. Hay también un resumen más actualizado en V. Martínez, Algunas reflexiones, pp. 11-28.

${ }^{3}$ Al-Hìmyarī, Kitāb al-Rawḍ, p. 72; Ibn 'Id̄ārī, Kitāb al-Bayān, I, p. 292.

${ }^{4}$ E. Molina, De nuevo sobre el reconocimiento público, pp. 793-812.

${ }^{5}$ Al-Ḥimyarī, Kitāb al-Rawd, pp. 144-146; Ibn 'Id̄ārī, Kitāb al-Bayān, I, pp. 304-305.
} 
y la fama que le debió reportar la enemistad con el citado sayyid, su reputación fue acrecentándose hasta el punto de reunir un ejército y recibir el apoyo de una parte de la oligarquía mursí, entre ellos, el cadí de Murcia Abūl-Hassan al-Qastallilī . Tras dos escaramuzas, se apoderó de la capital y después de recibir el reconocimiento de sus habitantes -la $b a y^{c} a-$, proclamó la soberanía 'abbāsí y se intituló emir. De los dos cronistas citados, Ibn 'Id̄ārī hace una mención explícita al hartazgo de los andalusíes por el gobierno almohade; y, al parecer, ello fue la condición necesaria para que Ibn Hūd organizase una guerrilla y conquistase una ciudad, repitiendo así los mismos movimientos que sus predecesores almohades ${ }^{7}$. A partir de ahí, las demás revueltas debieron contar, por lo menos, con el concurso de una gran población y fue de esta manera cómo Ibn al-Ahmar pudo consolidar un nuevo emirato. Este hecho ha llevado a historiadores a considerar factores tan importantes como la capacidad de movilización de aquellos cabecillas, uno de los aspectos más evidentes de la sublevación hūdí.

La primera referencia a estas cuestiones la hizo en la década de 1940 I. de las Cagigas, quien llegó a preguntarse sobre el significado de estos movimientos $^{8}$. Este autor propuso una singular visión el fenómeno insurgente: su visión, resumida, venía a decir que la despótica administración almohade tensó de tal manera las relaciones con los habitantes del país que, cansados de su opresión y visto el resultado de la batalla de Las Navas, se rebelaron y los expulsaron de la península. Dotados de una excepcional conciencia de sî mismos, sublevados en muchas ciudades de al-Andalus, pasaron a reconocer al primer sublevado, a Ibn Hūd, fraguándose un improvisado estado que rápidamente degeneró en una "democracia un tanto populachera" (sic) que fue respondido por la nobleza andalusí con un levantamiento encabezado por Ibn al-Aḥmar. Así, dejando al margen interesados paralelismos, la cuestión de los alzamientos y la fragmentación de al-Andalus durante el siglo XIII era explicada como un movimiento popular y xenófobo. Esta tesis llegó a calar y, poco tiempo después, en las décadas de 1950 y 1960, A. Huici Miranda continuó por esta línea poniendo el acento en las dificultosas relaciones entre andalusíes y almohades ${ }^{9}$. Siguiendo este planteamiento, el desprestigio almohade aumen-

\footnotetext{
${ }^{6}$ Ibidem.

${ }^{7}$ Ibidem: "Hubo otra vez gente que se adhirió a Ibn Hūd, y se dirigieron al lugar conocido por al-Șujayrāt, en las cercanías de Murcia y allí lo proclamaron. Se enteró la gente de esto y corrieron a él los ligeros y los pesados, jinetes y peones, por saber lo ocurrido entre los almohades y sus emires" (p. 305).

${ }^{8}$ I. de las Cagigas, Los mudéjares, p. 352 y ss. También recogido en idem, Sevilla almohade, pp. 23-33.

${ }^{9} \mathrm{La}$ referencia empleada en las propias fuentes árabes se corresponde a un clima de tirantez creado por la ejecución de un conocido miembro de la aristocracia andalusí, el $q \bar{a}$ ’id andalusí 
tó con las pugnas sucesorias mientras castellanos y aragoneses incrementaban sus incursiones; en consecuencia, así se entendía el clima reinante en las revueltas anti-almohades recogido por una fuente tan poco sospechosa como la Primera Crónica General, que mencionaba la destrucción de propiedades, el asesinato de personas y la posterior expulsión de los supervivientes ${ }^{10}$.

Años más tarde, gracias al estudio de las estructuras de poder a partir de nuevas fuentes arqueológicas y bio-bibliográficas, P. Guichard aportó novedosos planteamientos sobre la naturaleza de aquellos movimientos políticos andalusíes. Sus ideas presentaban una singular visión de la realidad social de un al-Andalus con linajes militares y un aparato burocrático y administrativo, cuya influencia se hallaba relativamente coartada por complejos mecanismos socioeconómicos ${ }^{11}$. Su análisis también abordó la tensión existente entre almohades y andalusíes, ya que, como se había comprobado desde hacía años, la lectura de las fuentes tanto árabes como castellanas no dejaba lugar a dudas sobre esa cuestión ${ }^{12}$. Guichard hizo hincapié en el desprestigio de los dominadores, un desprestigio acrecentado por las derrotas de Tejada y ${ }^{\mathrm{c} A f s}$ que demostraban su incapacidad para contrarrestar las cada vez más profundas incursiones castellano-aragonesas ${ }^{13}$. Para comprender el carácter de la insurrección hūdí y las consiguientes revueltas de las ciudades, el historiador francés aportó una sugerente visión sobre el ambiente cultural de al-Andalus, señalando que la violenta reacción de los andalusíes y los significativos ritos de purificación de las mezquitas mencionados por la Primera Crónica General podrían tener un significado mucho más profundo que una mera reacción sociopolítica. Ese significado podría haberse concretado en la estrecha relación entre los Banū Hūd y la popular corriente sufí mística denominada "sab'īnî", uno de cuyos principales focos se hallaba precisamente en el Valle de Ricote ${ }^{14}$. Aunque Guichard llamaba a la prudencia en este último punto, lo cierto es que la originalidad de su propuesta radicaba no sólo en la presencia de aquella corriente -en consonancia, dicho sea de paso, con las leyendas sobre el ascenso de Ibn Hūd, una de las cuales recogió Ibn 'Id̄ārī- sino en que el "ambiente cul-

Abūl-Ḥaŷȳâŷ Yūsuf b. Qādis, șăhịib de la fortaleza de Calatrava en 1212. Véase: al-Himyarī, Kitāb al-Rawd, pp. 164-165.

${ }^{10}$ La Primera Crónica General, en el capítulo 1037, dice a propósito de Ibn Hūd al-Mutawakkil: "descabeço et todos los almohades que auer pudo; et dando por suzias, ante los almohades, todas las sus mesquitas, fizolas alinpiar a los sus saçerdotes et lauarlas con agua commo fazen los christianos por las iglesias quando las rrestolan que son violadas" (p. 721).

${ }^{11} \mathrm{P}$. Guichard, Al-Andalus frente a la reconquista, passim.

${ }^{12}$ Ibidem, p. 160.

${ }^{13}$ Ibidem, p. 167.

${ }^{14}$ Ibidem, pp. 168-171. La relación de los Banū Hūd se materializa en Hasan b. Hūd que pasó a Damasco y allí llegó a ser jefe de la secta sab'īnī hasta su muerte en 1299 o 1300. 
tural" del Šarq al-Andalus justificaría posteriores subversiones locales como la célebre Wizāra 'Ișāmiyya de Orihuela así como el papel desempeñado por Abū 'Abd Allāh Muhammad b. 'Alī b. Aḥlī en Lorca en $1242^{15}$.

A la vez que P. Guichard planteaba su hipótesis, E. Molina López abordó los acontecimientos del siglo XIII a partir del estudio de los documentos oficiales del Kitāb Zawāhir al-fikar de Muhammad b. al-Murabīṭ. Partiendo de que las revueltas andalusíes se originaron como una reacción, aquel autor apuntó la importancia de que aquellas hubieran prosperado bajo un proyecto político coherente. La solidez de esta afirmación ha supuesto una significativa aportación historiográfica para entender la primera mitad del siglo XIII. La idea, que giraba en torno a la importancia del reconocimiento público del poder político, es que cuando en 1228 se sublevó Ibn Hūd éste buscó tanto una forma de robustecer su movimiento como de restaurar la legitimidad doctrinal previa a la invasión almohade, es decir, la soberanía de los 'abbāsíes ${ }^{16}$. A la vez, este reconocimiento por parte de un poder político superior servía para obtener una destacada preeminencia respecto a cualquier otro rival.

Recientes estudios han consolidado las líneas abiertas por P. Guichard y E. Molina López, profundizando en las características culturales e ideológicas de la transición almohade a las terceras taifas. Estos estudios han permitido elidir el papel pasivo de la aniquilación almohade en al-Andalus al mostrar la significativa importancia de su legado ideológico en manos de sus sucesores tanto en el norte de África como en al-Andalus ${ }^{17}$. Los rasgos fundamentales de estos estudios parten de la base del poder almohade como continuador de la unidad islámica en el Occidente musulmán, cuyos precursores habrían sido los omeyas y los almorávides. Este último movimiento y el almohade, ambos de fuertes connotaciones mesiánicas, habrían impregnado el imaginario colectivo de tal forma que hizo que sus sucesores estuvieran sólidamente convencidos de su papel exclusivo; y ello terminaría por dar una explicación coherente y lógica a la frenética búsqueda, por parte de cada sublevado, del reconocimiento público -la denominada $b a y^{c} a-$ y político, a través de las embajadas a 'abbāsíes o a ḥafșíes. Desde este punto de vista, el posicionamiento de los fugaces poderes, uno frente a otro, adquiere un significado mucho más amplio: se trataría de la aspiración a identificarse como sucesores de una legitimidad restaurada como les gustaba a estos estados que sus

${ }^{15}$ Leyenda que recoge Ibn 'Id̄ārī está en su Kitāb al-Bayān, I, pp. 303-305.

${ }^{16}$ E. Molina, De nuevo sobre el reconocimiento, pp. 793-812.

${ }^{17}$ Partiendo de la valiosa actualización historiográfica de M. J. Viguera (Historia política, pp. 39-143) conviene considerar los trabajos de M. I. Fierro, Doctrinas y movimientos, pp. 171 y ss. y Le mahdi Ibn Tûmart, pp 107-124 así como la citada síntesis de V. Martínez, Algunas reflexiones, pp. 11-28. 
súbditos y los (...) extranjeros contemplaran de qué forma ejercían el poder de hecho ${ }^{18}$. La trascendencia de esta visión estaría justificada por la aparición de corrientes renovadoras como la de Ibn Qasī de Silves o la de Ibn Sab`̄̄n de Ricote, cuya difusión en al-Andalus quedaría reflejada en la importancia de los habitantes de las ciudades, a través de unas "corrientes de opinión" que contribuyeron a aupar o deponer elites políticas ${ }^{19}$. Cuestión aparte, que se tratará de dilucidar aquí, es averiguar en qué grado esas corrientes de opinión se producían gracias a la influencia de destacados linajes, que terminaron obteniendo y manteniendo el poder mediante la violencia, como el murciano 'Azīz b. Jațāāb o el también citado Muḥammad b. 'Alī b. Aḥlà de Lorca ${ }^{20}$.

Esta última pregunta, junto a las referidas a la propia sublevación de Arjona de 1232 llevada a cabo de Muhammad b. Nașr, necesitan una respues$\mathrm{ta}^{21}$. Este movimiento y los demás surgidos en al-Andalus a partir de 1228 invitan a preguntarnos por el estado de las condiciones materiales de los habitantes de al-Andalus, centrándonos sobre todo en Murcia y a cuestionarnos, en definitiva, la integridad de aquella estructura institucional del poder político y social andalusí, fuertemente organizada, que distribuía y sostenía a la clase dirigente a través de una extendida red fiscal, como indirectamente apuntan, entre otros, Ibn 'Id̄ārī, Ibn Sā̄̄d, al-Murābiṭ o la Primera Crónica General, y como también indican numerosos registros arqueológicos.

\section{UNA HIPÓTESIS PARA EL ESTUDIO DE LAS REVUELTAS URBANAS}

Tres son los puntos de observación para apoyar la hipótesis aquí planteada sobre la génesis de las revueltas urbanas. En primer lugar, el contexto de crisis demográfica en que se desarrollaron, donde la carestía de alimentos

\footnotetext{
${ }^{18}$ V. Martínez, ibidem, p. 28. Otro medio para cimentar la legitimidad de cara al pueblo fue el empleo de la moneda cuadrada tal y como lo había hecho el régimen anterior. Véase: M. Vega, S. Peña, M. C. Feria, El mensaje de las monedas, passim.

${ }^{19}$ M.I. Fierro, Doctrinas y movimientos, pp. 171 y ss.

${ }^{20}$ E. Molina, De nuevo sobre el reconocimiento, pp. 793-812 y Aziz b. Jattab, pp. 63-86. De los tres movimientos, probablemente el más significativo y, a la vez, el menos conocido sea el del lorquino recogido por Ibn al- 'Abbār: "Muhammad ben 'Alī ben Aḥlà se proclamó emir (...) Era de una familia muladí de rancio abolengo: entre la gente de Lorca no la había ni más valiente ni más numerosa (...) Cuando sus habitantes entregaron Murcia a los cristianos (...) consideró errónea tal decisión y manifestó su oposición polemizando con ellos con su lengua y batiéndose contra ellos con su lanza" (p. 243).

${ }^{21}$ Una interesante síntesis sobre el alzamiento de Ibn Nașr puede leerse en F. Vidal, Frontera, genealogía y religión, pp. 793-810. En su Política, instituciones, espacio, passim, hace balance de su origen; también B. Boloix, De la Taifa de Arjona, passim, trata la cuestión con notable rigor. Sobre el desconcierto que aún causa en la historiografía su aparición y triunfo léase la observación al respecto de V. Martínez: Algunas reflexiones, pp. 23 y ss.
} 
y la presión militar de castellanos y aragoneses llegaron a tan altas cotas que movió a la población a buscar refugio. En segundo lugar, pretendemos incidir en la posibilidad de que los grandes núcleos de población fueran "sumideros" donde iban aquellos que buscaban protección frente a las citadas acometidas; y ello nos conduce a tratar de demostrar si existen vestigios que lo atestigüen. Finalmente, para la construcción de esta hipótesis intentaremos esclarecer los medios materiales con que contaron los poderes fugaces para reivindicarse y consolidar sus dominios; ello quiere decir que, en el seno de una sociedad agraria como la del siglo XIII, esos medios debían tener su origen en la tierra, concretamente en el caso de Murcia, en su huerta.

\subsection{Hambrunas, cabalgadas y desplazamientos de población}

Importantes fuentes escritas que refieren los hechos del siglo XIII aluden repetidamente a la escasez de recursos como un factor relevante en el desarrollo de los acontecimientos. Lo que inicialmente parecían estar reflejando -los efectos de la actividad militar castellano-aragonesa- en rigor relatan una sucesión de eventos medioambientales que, en el seno de una sociedad agraria, afectaron tanto al Mediterráneo Occidental como al resto de Europa.

En efecto, investigaciones centradas en el ámbito anglosajón y centroeuropeo no dudan en identificar un breve pico climático cálido en la Edad Media que se ha concretado entre los años 1100 y 1200, caracterizado por unos veranos secos, unos suaves inviernos y una proliferación de anomalías hidrológicas, todo ello acompañado de una elevada actividad solar; este evento climático no sería sino el precedente del enfriamiento de Europa a partir de la mitad del siglo XIII que, a su vez, actuó como preludio al enfriamiento global registrado entre los años 1550 y $1850^{22}$. Aunque es evidente que la península ibérica y el norte de África se sitúan en una posición marginal con respecto a aquellos estudios, es probable que, en aquel contexto global, hubiese un largo periodo de suaves temperaturas en la península que, al romper la tendencia anterior, influyera en la productividad de la tierra a corto plazo. De hecho, existen indicios de una crisis alimentaria en el Mediterráneo Occidental y, aunque todavía son pocos los estudios sobre su economía agraria en los siglos XII y XIII, cabe señalar una importante coincidencia en las

\footnotetext{
${ }^{22}$ R.S. Bradley et al, The climate of the last millennium, pp. 105-141. Sobre el periodo cálido medieval hay dos trabajos a tener en cuenta: el de H.H. Lamb, The early Medieval warm epoch, pp. 13-37 y una interesante crítica de H. Goosse et al.,The origin of the European, pp. 99-113.
} 
fuentes ${ }^{23}$. Ello es debido a que, a partir de finales del siglo XII -desde 1195 según R. Vernet-, se produjo una secuencia de depresiones en la producción de grano en el Magreb que duró prácticamente todo el siglo XIII. En este contexto, la cita más temprana es recogida por la Primera Crónica General en referencia al reinado de Alfonso VIII, cuando dedica un fragmento a una gran hambruna ocurrida poco tiempo después de la conquista de Alcaraz en $1213^{24}$. Luego, en referencia a un cerco sobre Baeza, la misma fuente vuelve a aludir al problema de abastecimiento que alcanzó de lleno a la hueste real ${ }^{25}$. Las fuentes árabes, por una de esas coincidencias extraordinarias, se hacen eco de la misma situación y apuntan a una extraña y prolongada escasez. Esto se observa a través de dos cronistas: al-Murābiț, testigo directo, que relató un panorama desolador ${ }^{26}$; e Ibn Abi Zarc ${ }^{c}$, posterior, que se refirió a la lamentable condición vivida en 1227: por ese tiempo hubo en al-Andalus y en al-Magrib una terrible carestía y una peste gravísima, que desoló muchas provincias; llegó a valer el cahíz de trigo ochenta dinares; unas líneas después, al narrar los años 1237 y 1238, añade que hubo, al otro lado del Mediterráneo, una gran carestía y una terrible epidemia, y llegaron a comerse unos a otros ${ }^{27}$. Así, con los datos de numerosas fuentes de la época, R. Vernet computó los ciclos de carestía en los años 1195, 1220, 1226-1227, 1230, 1232-1242, $1281,1294,1308-1311$ y $1323-1324$ (tabla 1 ), datos que concuerdan a grandes rasgos con otros ciclos puestos de relieve por F. Menant y P. Benito en Europa Occidental ${ }^{28}$.

\footnotetext{
${ }^{23}$ Un estudio fundamental es el de R. Vernet, Recherches sur la production, pp. 31-62. Un resumen de este trabajo, centrado en el siglo XIII, en idem, La production céréalière, pp. 253268. Algunos datos provienen del trabajo previo de H.R. Idris, Contribution à l'étude de la vie économique, pp. 75-87. R. Arié, se hace eco de esta cuestión y señala claramente una sequía como causante del descontento de 1227 en su España Musulmana, p. 35.

${ }^{24}$ Primera Crónica General, cap. 1022, p. 706.

${ }^{25}$ Ibidem, cap. 1023, p. 706-707. En tiempos del Fernando III, dada la situación de carestía, Castilla llegó a paralizar sus operaciones tras la consolidación de Córdoba y sus alrededores. Véase: J. González, Las conquistas de Fernando III, pp. 515-631. Sobre las necesidades de abastecimiento de un ejército en campaña durante la Edad Media puede leerse el trabajo de M. Sánchez, Guerra y avituallamiento, pp. 523-549.

${ }^{26}$ Al-Murābiț, apud Abūl-Mutarrif b. 'Amīra. Algunos fragmentos se hallan recogidos en el trabajo de E. Molina, El Levante y Almería, p. 60: "el hambre es general en todas partes y la pobreza no conoce unos límites como éstos. Ni cebada ni trigo. En cuanto al pan amasado, eso no tiene nombre. Hay una razón en todo ello, la falta de medios y la ignorancia".

${ }^{27}$ Ibn Abī Zar', Raw du al-Qirțās, passim. Hay constancia de más citas de este cronista norteafricano sobre calamidades alimenticias en el Magreb a partir de las referencias que hace R. Vernet: La production céréaliere, p. 267 (nota 89).

${ }^{28}$ F. Menant, Crisis de subsistencia, pp. 17-60. Véase, también, el anexo 1 del trabajo de P. Benito, Fams i caresties.
} 
Tabla 1. Producción, importación y exportación de grano entre los siglos XII - XIV

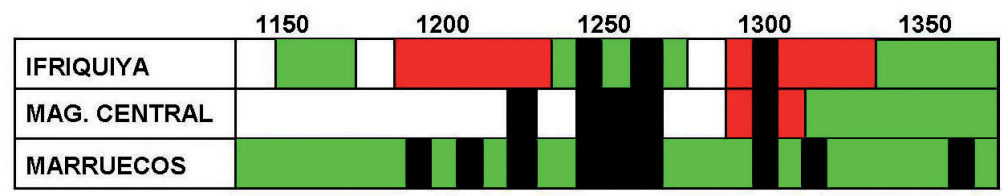

Exportación de Grano

Periodos de hambre o escasez

Importaciones de Grano

Fuente: R. Vernet, La production céréalière dans le Maghreb p. 266

Desde el punto de vista propuesto, resulta atractiva la idea de asociar el ciclo de carestía de 1226-1227 a la sublevación hūdí de 1228 y el largo ciclo de 1232-1242 al inicio de la decadencia del movimiento hūdí y a la emancipación de Ibn al-Ahmmar ${ }^{29}$. Más aún, especial atención merece la crisis de mitad de siglo, entre los años 1257 y 1258 -causada por una violenta erupción volcánica en un lugar todavía indeterminado del planeta- que afectó al continente en forma de malas cosechas, migraciones y mortandades, y que podría ser relacionada con la sublevación mudéjar de $1264^{30}$. Conviene, por último, llamar la atención sobre el hecho de que la frecuencia de los ciclos de carestía comenzó a remitir a partir del último cuarto del siglo XIII, momento en el cual se fijó la frontera castellano-nazarí.

Hay más. Si la escasez, las enfermedades y el hambre causaron estragos en al-Andalus en la primera mitad del siglo XIII, la proliferación de cabalgadas -un fenómeno acrecentado desde la crisis institucional almohade- es un hecho documentado que mermó aún más la ya de por sí endeble situación de sus habitantes. Y es que, tras la sublevación de al-'Adil, se advierte tal energía

${ }^{29}$ Existe constancia de que Ibn al-Jațīb ( $A^{c} m a \bar{a} l$, p. 275), muy cuidadoso en sus apreciaciones, hace referencias a una falta de recursos económicos con el consiguiente malestar entre la población durante el periodo en el que sucedieron los acontecimientos del movimiento hūdí. Véase: E. Molina, Aziz b. Jattab, p. 83.

${ }^{30}$ R.B. Stothers, Climatic and demographic consequences, pp. 361-374. De momento, la crisis de 1257 encuentra su eco en Aragón, según ha sintetizado brevemente C. Laliena, Licencias para la exportación, p. 446 (nota 2). Puede el lector quedarse con el dato de Ibn 'Idāāī (Kitāb al-Bayān, II, p. 294) quien señaló que hacia el 1264-1265 hubo en al-Andalus una gran carestía de forma que la adquisición de alimentos se había hecho difícil. 
desplegada por Castilla y Aragón, que se materializó en una serie de embestidas muy breves y destructivas, que dejaron una fuerte impresión entre los musulmanes, como lo demuestra el hecho de que, antes de la conquista de Valencia, de Jaén o de Murcia, estas ciudades ya había sido sometidas a asedio ${ }^{31}$. En los textos tanto árabes como castellanos se pueden hallar sólidas noticias de profundas incursiones de castellanos y aragoneses en territorio andalusí que llegaron a ocasionar fuertes destrozos. Las referencias más cercanas a los acontecimientos se localizan en el reinado de Alfonso VIII -aunque la información ofrecida es muy general y precede a la toma de Cuenca- cuando se hace una relación muy amplia de los efectos de las cabalgadas ${ }^{32}$. En este sentido, resultan muy importantes dos fragmentos del texto. El primero: cortoles las huertas et los logares de sus annazeas o fazien sus deleytes et tomauan sus solazes; y el segundo: ençerro los alaraues con la su uenida. Por su parte, las fuentes musulmanas también hacían continuas alusiones a este fenómeno de hostigamiento en sus territorios; eso lo relató con posterioridad Ibn Jaldūn, pero también se comprueba por un cronista de la época, al-Himyarī, al referirse a la derrota de los mursíes en las batallas de Tejada y 'Afș en $1225^{33}$.

Resulta imposible no relacionar la enorme presión de las algaradas castellano-aragonesas con la situación de efervescencia social que precipitó el surgimiento del movimiento hūdí, sobre todo, si se contrastan las fechas. Más aún, las fuentes muestran que el fenómeno de las cabalgadas subsistió durante todo el periodo "revolucionario" de Ibn Hūd, lo que a la postre influyó en la atomización política de al-Andalus a la muerte de aquél. Salvo la citada referencia de la Primera Crónica General, las fuentes silencian las consecuencias de aquella actividad militar, pero es evidente que el resultado de un panorama tan violento no debió ser otro que la huida y concentración de población en lugares fácilmente defendibles ${ }^{34}$. De hecho, este fenómeno no fue exclusivo del siglo XIII; por ejemplo, M. Rodríguez Llopis, a propósito de las despoblaciones de los territorios santiaguistas del reino de Murcia señalaba:

\footnotetext{
${ }^{31}$ Ibn Jaldūn, en su Kitāb al-'Ibar, p. 306, dice: “durante el año 633 (1235-1236) los musulmanes soportaron siete asedios: dos en Valencia, uno en la isla del Júcar (Alcira) y Játiva, uno en Jaén, uno en Tavira, uno en Murcia y uno en Niebla".

${ }^{32}$ Primera Crónica General, cap. 999, pp. 678-679. En la Crónica hay más referencias a este mismo sistema de incursiones y destrucción intencionada del paisaje agrario andalusí con fines militares en las páginas 679, 686, 688 y entre las páginas 720 y 721 .

${ }^{33}$ Al-Himyarī, Kitāb al-Rawd, p. 163.

${ }^{34}$ En realidad la idea no es nueva. J. González (Población en la nueva tierra, pp. 76-77) señaló en su momento que un proceso de concentración de población se había estado produciendo en Andalucía -Córdoba, Écija, Andújar, Baeza y Úbeda- a tenor de las incursiones castellanas desde finales del siglo XII.
} 
El despoblamiento se constituye en la consecuencia lógica de una sociedad que vive para la guerra; la población se contrae para mejor defenderse, y en ello encuentra su pervivencia, como hemos observado al analizar las formas de defensa urbana. Aquellas comunidades que no encontraron alternativas frente a la inestabilidad bélica sólo pudieron perdurar por breve tiempo, para, al final, desaparecer ${ }^{35}$.

\subsection{La fragmentación del parcelario y su crecimiento en altura}

Es un hecho que la agrupación para la defensa debió repercutir de modo patente en la organización y comportamiento del poblamiento de la última taifa de Murcia. Es factible pensar que el modo más lógico y sensato para evitar las acometidas hostiles en territorio propio fuera el de proveerse de una red de fortificaciones tanto en las cercanías de las ciudades como en los espacios rurales más recónditos: como los datos arqueológicos parecen no cuestionar este supuesto, no es de extrañar que el panorama de la primera mitad del siglo XIII fuera el de una sociedad muy concentrada y extremadamente dependiente de estas fortificaciones para su defensa ${ }^{36}$. En ese sentido, la ciudad y su entorno fortificado tenían que ser fundamentales hitos defensivos.

Dentro de las ciudades, el elemento más importante y representativo que puede demostrar un fenómeno de concentración no es el de su fortificación, que se presupone, sino la vivienda. Ésta puede indicar la cantidad o el tipo de habitantes que disponía la ciudad en el periodo que se estudia. En consecuencia, si hubo una necesidad de protección y se produjo una concentración de población en los principales núcleos habitados, será necesario poder comprobar si las viviendas muestran, de alguna manera, este fenómeno. Existe un precedente: A. Bazzana llegó a la conclusión de que su compleja estructura había parecido casi invariable durante toda la dominación islámica; y que solamente se produjo una sustancial transformación a causa del "ajuste" del poblamiento como efecto de la emigración cuando se generaron los hábitats moriscos ${ }^{37}$.

En la ciudad de Murcia se ha documentado hacia la mitad del siglo XII, además de viviendas comunes de una media de $84 \mathrm{~m}^{2}$, de un sólo patio y sus cuatro crujías ordenadas en torno a él, un tipo de vivienda amplio, complejo, compartimentado en varias células con patio propio y, a la vez, interconec-

\footnotetext{
${ }^{35}$ M. Rodríguez Llopis, Señoríos y feudalismo, p. 51.

${ }^{36}$ Una publicación acerca al lector al panorama fortificado en el territorio del río Segura durante el siglo XIII: D. Munuera, J.A. Martínez, Por tierra de castillos, passim.

37 A. Bazzana, Maisons d'al Andalus, pp. 355-376.
} 
tadas entre sí por pasillos u otras soluciones arquitectónicas. Las excavaciones arqueológicas que han datado las del siglo XII, coinciden en señalar, entre grupos de casas más reducidas, este tipo de vivienda (tabla 2$)^{38}$.

Tabla 2. De la superficie de viviendas de Murcia entre los siglos XII y XIII

\begin{tabular}{|l|l|l|}
\hline GARAJE VILLAR & CRONOLOGÍA & SUPERFICIE $\left(\mathrm{m}^{2}\right)$ \\
\hline UBICACIÓN & XII & 180 \\
\hline Vivienda 1 & XIII & 90 \\
\hline Vivienda 2 & XII - XIII & 100 \\
\hline Vivienda 3 & XII & 300 \\
\hline Vivienda 4 & XII & 140 \\
\hline Vivienda 5 & XII & 80 \\
\hline Vivienda 6 & XIII & 100 \\
\hline Vivienda 7 & XI & 100 \\
\hline Vivienda 8 & XIII & 60 \\
\hline Vivienda 9 & XIII & 90 \\
\hline Vivienda 10 & XII - XIII & 150 \\
\hline Vivienda 11 & XIII & 100 \\
\hline Vivienda 12 & XII - XIII & 65 \\
\hline Vivienda 13 & & \\
\hline
\end{tabular}

\begin{tabular}{|l|l|l|}
\hline PLATERÍA, 31, 33 y 35 & CRONOLOGÍA & SUPERFICIE $\left(\mathrm{m}^{2}\right)$ \\
\hline UBICACIÓN & XI - XIII & 90 \\
\hline Vivienda 1 & XI - XIII & 55 \\
\hline Vivienda 2 & XI - XIII & 30 \\
\hline Vivienda 3 & XI - XIII & 60 \\
\hline Vivienda 4 & XI - XIII & 60 \\
\hline Vivienda 5 & XI - XIII & 55 \\
\hline Vivienda 6 & XII & 250 \\
\hline Vivienda 7 & & \\
\hline
\end{tabular}

${ }^{38}$ Ibidem, pp 196-197; véase también: J. Manzano, Memoria preliminar de los trabajos, p. 395. En efecto, en Murcia están presentes desde siempre los dos tipos edilicios desde el siglo $\mathrm{X}$ u XI que es cuando se empiezan a detectar niveles arqueológicos claramente contextualizados. Los tamaños de las grandes mansiones mejor documentadas son: el palacete de la calle Fuensanta, $850 \mathrm{~m}^{2}$; la casa ${ }^{\circ} 4$ del Garaje Villar, $300 \mathrm{~m}^{2}$; la casa $\mathrm{n}^{\circ} 7$ de Platería $31-35,250 \mathrm{~m}^{2}$; y el palacete de la calle Pinares, $700 \mathrm{~m}^{2}$. 


\begin{tabular}{|l|l|l|}
\hline \multicolumn{2}{|l|}{ TRAPERÍA, 36-38 } & CRONOLOGÍA \\
\hline UBICACIÓN & XI - XIII & SUPERFICIE $\left(\mathrm{m}^{2}\right)$ \\
\hline Vivienda 1 & XI - XIII & 44 \\
\hline Vivienda 2 & XI - XIII & 120 \\
\hline Vivienda 3 & XI - XIII & 50 \\
\hline Vivienda 4 & XI - XIII & 75 \\
\hline Vivienda 5 & XI - XIII & 60 \\
\hline Vivienda 6 & & 77 \\
\hline
\end{tabular}

Fuente: J. Manzano Martínez, Memoria preliminar de los trabajos arqueológicos en el subsuelo de la actual plaza de Europa. pp. 333-398; J.A. Ramírez Águila, J.A. Martínez López, Introducción al urbanismo de la Murcia islámica. pp. 556 y ss.; J. Manzano Martínez, Aproximación a la estructura de la propiedad.pp. 61-75.

Y precisamente esas viviendas de gran porte fueron las que más sufrieron una perceptible transformación durante los últimos años del siglo XII y la primera mitad del siglo XIII. De hecho, salvo excepciones muy puntuales, se ha detectado en numerosos solares de Murcia la mutación de ese modelo doméstico singular representado en la fragmentación de las viviendas, generando en ocasiones casas más pequeñas. Por ejemplo, en un palacete de aproximadamente $850 \mathrm{~m}^{2}$, al referirse a los niveles correspondientes a los siglos X y XI, sus excavadores no dudaban en plantear una ordenación familiar fuertemente jerarquizada, con ámbitos muy bien definidos y articulados a través de un gran patio central, aspecto que les sugería una familia patriarcal controlada, en gran medida, por una sola persona (fig. 1$)^{39}$.

Pero el edificio fue cambiando con el paso del tiempo: para los últimos años del siglo XII y la primera mitad del siglo XIII, se hacía especial mención a una mayor individualización de sus ámbitos; entonces la vivienda era todavía una sola unidad (fig. 2) ${ }^{40}$.

La definitiva fragmentación - una fortísima fragmentación donde los ámbitos comunes dejaban de tener alguna relación- vendría en la primera mitad del siglo XIII ${ }^{41}$. Parecía que, por fuerza y necesidad, se había introducido gente nueva sin ninguna relación entre sí; no cabe otra explicación, ya que si los habitantes de las viviendas hubieran pertenecido a un tronco común, ¿por

${ }^{39}$ M. Bernabé, J.D. López, El Palacio Islámico, pp. 18, 61-62.

${ }^{40}$ Ibidem, pp. 62-63.

${ }^{41}$ Se correspondería con la fase IV (pp. 31-32: fig. 10 y 11). Los autores no dudaron en calificarlo como "etapa de empobrecimiento de los materiales y de división definitiva". 


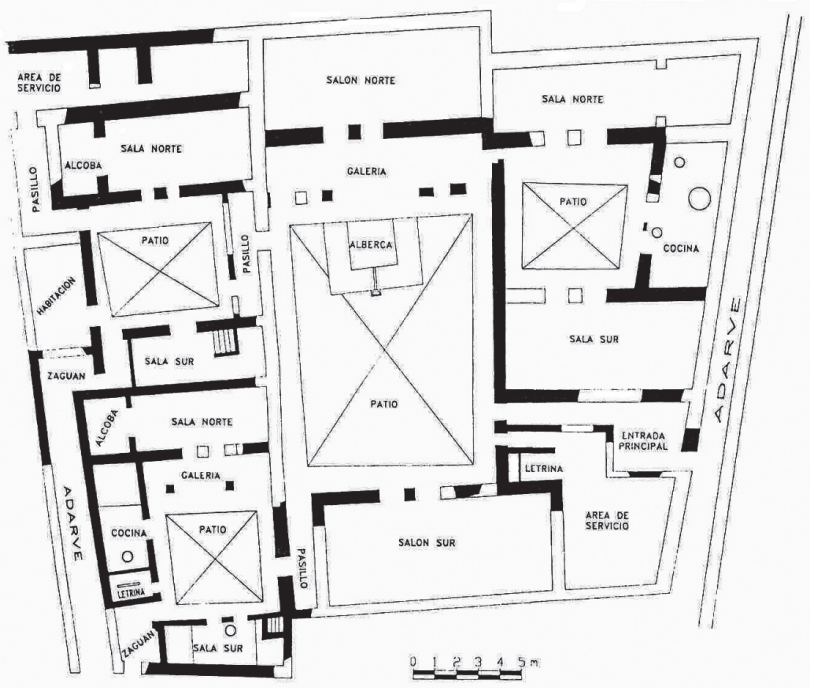

Fig. 1. Planta del palacete de la calle Fuensanta. Síntesis de los niveles correspondientes a finales del siglo X y todo el siglo XI. Fuente: M. Bernabé, J.D. López, El Palacio Islámico, p. 20, fig. 5.

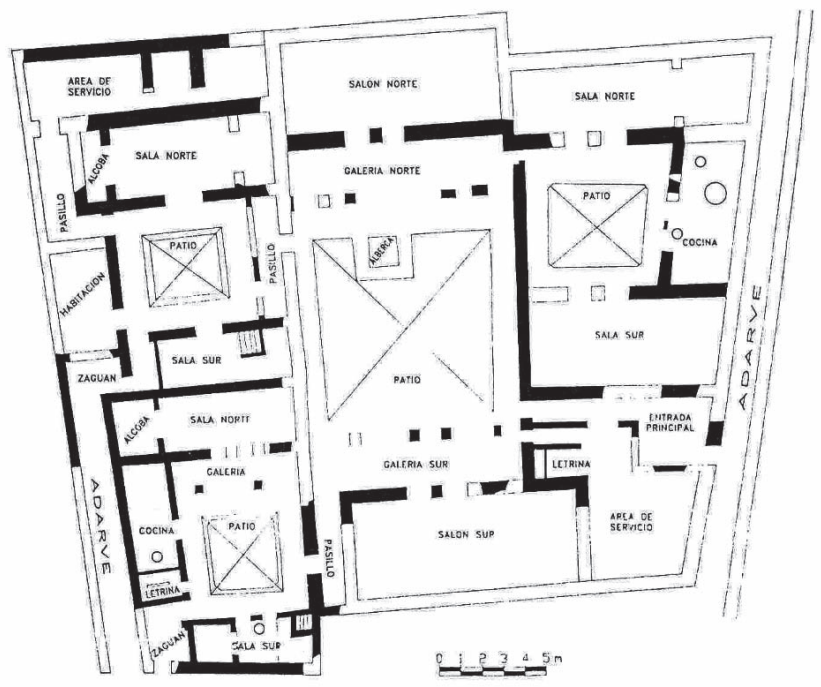

Fig. 2. Planta del palacete de la calle Fuensanta. Síntesis de los niveles correspondientes al siglo XII y primera mitad del siglo XIII. Fuente: M. Bernabé, J.D. López, El Palacio Islámico,p. 27, fig. 7. 
qué esa radical ruptura con la etapa precedente? $?^{42}$. Este fenómeno se ha podido documentar en otras mansiones de Murcia como en las excavaciones de la calle Marengo, donde una amplia vivienda se fragmentó en dos. O en Platería 14, donde los ámbitos C y B quedaban ligados por un pasillo que unía ambos patios configurando una amplia vivienda en el siglo XII; y, sin embargo, para el siglo XIII, ambas casas ya se hallaban individualizadas, sus materiales se habían empobrecido, y el patio quedaba convertido en parte de la crujía occidental de la vivienda $\mathrm{B}$, lo que significaba que la relación parentelar se había deshecho (fig. 3$)^{43}$.

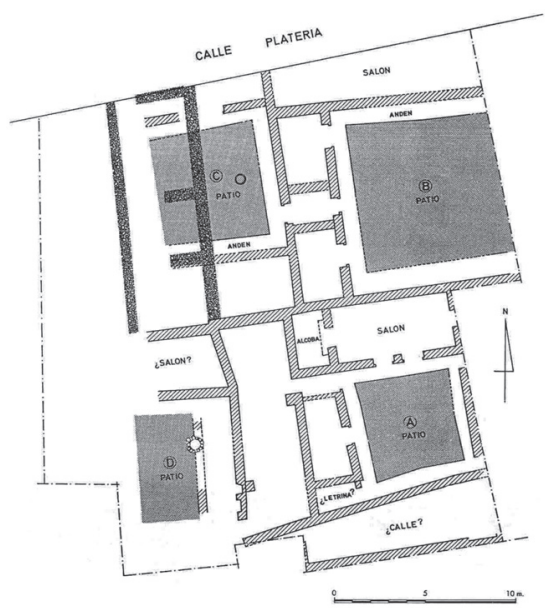

Fig. 3. Planta de la mansión urbana de la calle Platería 14. Contraste de los niveles del siglo XII (en claro) con los cambios del siglo XIII (en oscuro, correspondientes a la vivienda C).

Fuente: P. Jiménez, J. Navarro, Platería 14, p. 34.

\footnotetext{
${ }^{42}$ En otro caso más temprano de fragmentación de una vivienda -fechada inicialmente en el siglo XI y partida en el XII- sus investigadores llamaron la atención sobre el fenómeno indicando: "Más allá del fenómeno de partición, la casa califal (...) forma parte de un grupo de viviendas de esa época excavadas en la ciudad de Murcia (...) que podríamos denominar polinucleares por contar con más de un patio con sus dependencias asociadas. Este tipo de viviendas son proporcionalmente mucho más numerosas para estas fases antiguas que para los siglos XII y XIII. (...) Resulta tentador asociar esta transformación del arquetipo doméstico con cambios en el modelo familiar; sin embargo, debemos recordar que el contexto urbano en el que se sitúan ambos fenómenos es muy distinto pues las primeras se inscriben en una ciudad en expansión, con una urbanización semidispersa, mientras que las segundas forman parte de una urbe saturada, con todos los fenómenos de reducción de superficie, partición de fincas, ocupación de espacios públicos y crecimiento en altura de los edificios que conlleva". Véase: P. Jiménez, J. Navarro, Un ejemplo de saturación, pp. 781-802.

${ }^{43}$ M. Bernabé, Informe preliminar, p. 521; y P. Jiménez, J. Navarro, Platería 14, pp. 33-39. La excepción vendría de otros casos excavados. Por ejemplo, en San Nicolás se hallaba asociado a una amplia vivienda de aproximadamente $19 \mathrm{~m}$. de ancho por $25 \mathrm{~m}$. de largo que permaneció inalterable hasta la conquista. Otro tanto ocurría en el Garaje Villar, donde la casa 4 -una
} 
Fuera de Murcia, en Siyāsa, también se ha documentado un esquema de vivienda amplia, capaz de acoger a una familia extensa, posteriormente fragmentada. Es la casa 10, que luego dio origen a las viviendas 12 y 14 (fig. 4). Es muy posible -a juzgar por las evidencias arquitectónicas y a falta de que se determinen fases anteriores- que estos tres espacios formaran uno solo. De este modo, el patio de la casa 10 podría haber actuado de eje, eje que conservó para sí pero que no fue posible conservar para las casas 12 y 14 . Si se confirmara, este ejemplo corroboraría claramente el factor de descomposición de la vivienda en unidades menores como consecuencia de un anormal incremento demográfico que se produjo entre los siglos XII y XIII no sólo en la capital sino en otras localidades del territorio murciano ${ }^{44}$.

De hecho, a día de hoy existen datos de otras excavaciones con las que se podría seguir argumentando esta hipótesis: a modo de síntesis, puede observarse que la vivienda andalusí ofrecía, a principios del siglo XIII, un aspecto muy diferente al de los siglos precedentes como muestra la tabla comparativa de medidas de superficie; observando estos datos, es muy palpable su significativa disminución (tabla 2 ) $^{45}$. Más aún, si es cierto que se produjo una densidad de población en estos núcleos, otros elementos edilicios podrían

amplia mansión residencial urbana- permaneció inalterable durante los siglos XII y XIII salvo sustanciales modificaciones interiores ideadas para optimizar el espacio desde un punto de vista funcional. También, en Platería 31,33 y 35 se halló una amplia vivienda que no sufrió división durante el periodo islámico. Hace poco se ha publicado la excavación de una vivienda de grandes dimensiones en la plaza Santa Eulalia (solar $n^{\circ} 1$ - 3): era la casa A que fue excavada en una cuarta parte y que daba unas medidas aproximadas de $260 \mathrm{~m}^{2}$ con una cronología que arrancaba desde el siglo XI en adelante sin que se apreciaran cambios sustanciales salvo un crecimiento en altura. Finalmente, hay que señalar que probablemente sea el propio palacio emiral -la $D \bar{a} r$ al-Sugrà- el que muestre más claramente el mantenimiento hasta el siglo XIII de algunas residencias de poder, pero muy debilitadas por el empobrecimiento del Estado murciano antes y después de la dominación de los almohades. Sobre estas cuestiones véanse: J. Navarro (coord.): Una casa, pp. 20-28; idem, Un palacio protonazarí, pp. 177-206; J. Manzano, Memoria preliminar de los trabajos, pp. 333-398; J.A. Ramírez, J.A. Martínez, Introducción al urbanismo, pp. 550-551; y, M. Bernabé, Casas y cementerios, pp. 576-585.

${ }^{44}$ También se conoce el caso de la casa $\mathrm{n}^{\circ}$ 5. Señalan sus investigadores: "Además de su extensión (de unos $175 \mathrm{~m}^{2}$ ) presenta otras particularidades (...) La primera es la existencia de dos núcleos completamente diferenciados, con sendos patios pertenecientes a la misma vivienda. La segunda radica en el fuerte contraste entre la gran extensión de la casa y su pobre y exigua decoración arquitectónica. La tercera hace referencia al carácter adicional de la planta, pues no responde a una concepción unitaria sino que es el resultado de la incorporación de nuevos espacios a un núcleo inicial". Las evidencias arqueológicas analizadas por ellos apuntaban a un esquema fundacional que se conservó hasta el siglo XIII y que acogió a dos familias relacionadas a partir de un nexo como el que representaba un amplio zaguán. Véase: J. Navarro, P. Jiménez, Estudio sobre once casas, pp. 551 y ss.

${ }^{45}$ Debo señalar que, para este cálculo, he obviado el caso de aquellas excavaciones en las que no aparecía un número considerable de viviendas ni las que presentaban fragmentación de antiguas mansiones residenciales urbanas. Los datos de las dos últimas excavaciones provienen del trabajo de J.A. Ramírez, J.A. Martínez, Introducción al urbanismo, pp. 548-569; y, J.D. López, J.A. Sánchez, Excavación arqueológica de urgencia, pp. 60-62. 


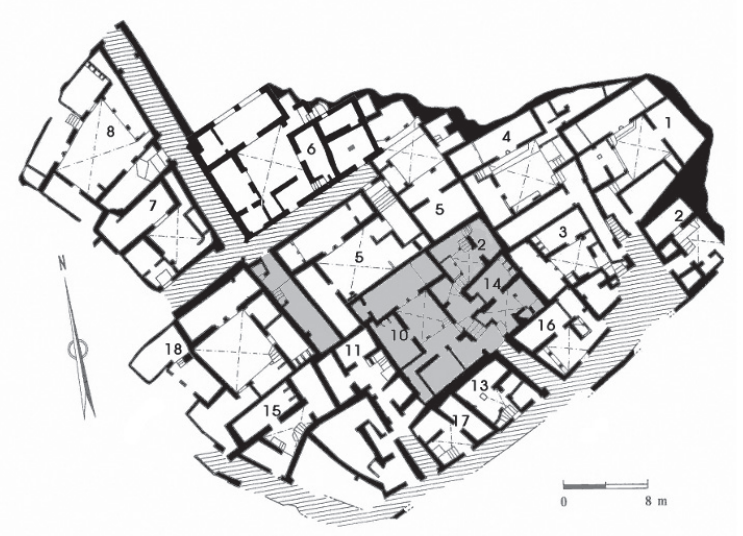

Fig. 4. Planta parcial de Siyāsa. A destacar las casas 10, 12 y 14 (sombreadas) que en su momento debieron formar una unidad; también conviene advertir el minúsculo espacio (sombreado) entre las viviendas 5 y 18 que cuenta con unas escaleras y contrafuertes y pudo, por tanto, constituir otra vivienda en altura. Fuente: J. Navarro, P. Jiménez, Estudio sobre once casas, pp. 528.

confirmar si eso fue una realidad. Y efectivamente los hay. Si la fragmentación del parcelario es señal de un importante crecimiento en la densidad de los núcleos de población, el crecimiento en altura también puede considerarse desde este punto de vista. Así, a partir de un momento en el desarrollo urbano, a la vez que el parcelario se saturaba, se pasó al crecimiento en altura a costa incluso de la ocultación de viales ${ }^{46}$. Este proceso urbano se consiguió apreciar inicialmente en Siyāsa, sobre todo, observando tanto la presencia de galerías porticadas como la potencia de los muros y la existencia de contrafuertes adosados a las paredes de algunas viviendas; fue fechado en el último cuarto del siglo XII y primer tercio del siglo XIII, es decir, durante el periodo almohade que se correspondería con la decoración de algunas galerías (fig. 4) ${ }^{47}$. Más arriba se ha señalado el caso de las viviendas 10,12 y 14 que podrían haber formado una sola. La fragmentación de aquella, de 168,52 $\mathrm{m}^{2}$, provocó la formación de dos casas de escasísima planta $-44,91 \mathrm{~m}^{2}$ y $32,96 \mathrm{~m}^{2}-$ y una, la casa 10, de 90,65 m², que mantenía tras la segregación una superficie todavía respetable para una familia; de ahí que se debiera promover la construcción de plantas altas.

${ }^{46}$ Sobre esta cuestión puede leerse el trabajo de J. García-Bellido, Principios y reglas morfogenéticas, pp. 59-86.

${ }^{47}$ J. Navarro, La casa andalusí, p. 178. 
También en la ciudad de Murcia se han hallado indicios de este crecimiento en altura. En la excavación de la calle Cortés se encontraron restos de lo que podrían haber sido dos viviendas con una planta alta: la casa 1 y la casa $6^{48}$. En la casa 1, de escaso tamaño $-49,6 \mathrm{~m}^{2}-$, se documentó el arranque de una escalera; se supuso que la planta alta se construyó para compensar la falta de espacios domésticos en la baja de lo que se deduce que antes no había vivienda alguna en su solar. La última reforma está fechada en los inicios del siglo XIII. La segunda de ellas era una vivienda de $183 \mathrm{~m}^{2}$ que tenía patio y tres crujías dispuestas en su entorno; en una segunda fase perteneciente al siglo XIII, se construyó un pórtico y una escalera para una planta alta. Tanto en uno como en otro caso, se cree que la planta alta volaba sobre el adarve. En la excavación del solar de Platería 31, 33 y 35 también se advirtió algo similar: se detectaron importantes contrafuertes en las paredes exteriores de las viviendas 1 y 4 ; y en las interiores de las viviendas 3 y 14 (fig. 5).

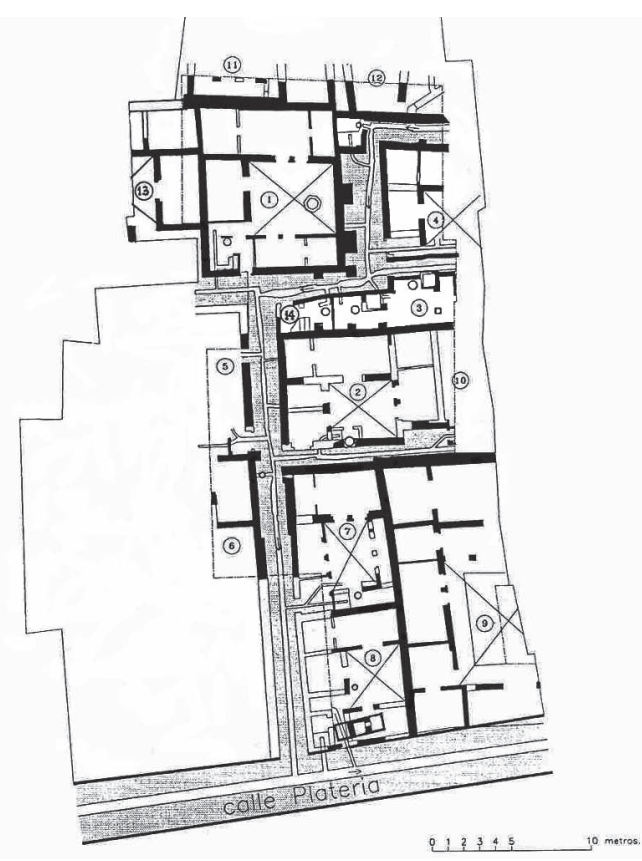

Fig. 5. Planta del solar de Platería 31, 33 y 35. Adviértanse los contrafuertes en las paredes exteriores de las viviendas 1 y 4 ; y en las interiores de las viviendas 3 y 14. También, las escaleras de esta última. Fuente: J. A. Ramírez , J. A. Martínez, Introducción al urbanismo, pp. 556 y ss.

\footnotetext{
${ }^{48}$ Esta excavación está doblemente estudiada. Por un lado por su excavador,F. Muñoz, Sobre la evolución de una manzana, pp. 416-436; y, por J. Navarro, P. Jiménez, Plantas altas en edificios, pp. 107-137.
} 
Y, por supuesto, llamó la atención la vivienda 14 que, de tan escasa superficie, parecía que se había construido a costa del adarve y que presentaba un arranque de escalera. Se desconoce donde pudo ubicarse la planta alta, aunque los contrafuertes pueden servir de pista: es decir, sobre las viviendas 3 y 14 y sobre el adarve que discurría hacia las viviendas 1,4 y 12 . En la casa A del solar 1-3 de Santa Eulalia también se documentó un crecimiento en altura sobre su alcoba sur. Este crecimiento, fechado en la primera mitad del siglo XIII, se evidenciaba por una escalera construida en ladrillo y por el recrecimiento de los muros oeste y sur de la vivienda (fig. 6). Finalmente, en la excavación del solar municipal de la plaza de Belluga, se logró documentar un posible crecimiento en altura en la vivienda 1 , fase 2 y 3 , perteneciente posiblemente a los siglos XII y XIII ${ }^{49}$.

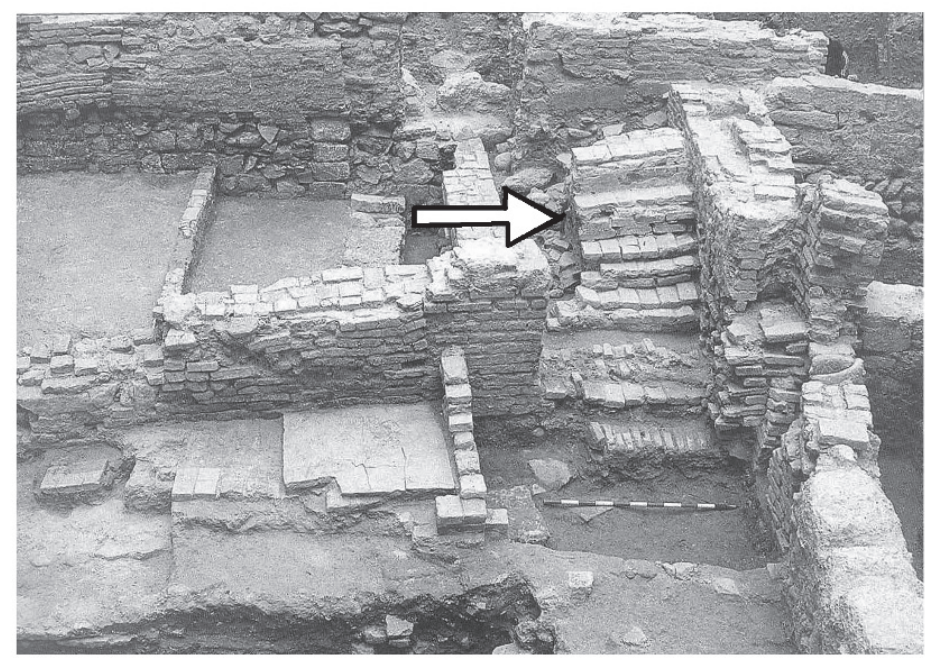

Fig. 6. Detalle de la crujía sur de la casa A del solar 1-3 de Santa Eulalia, donde se documentó un crecimiento en altura sobre su alcoba evidenciado por una escalera construida en ladrillo. Fuente: M. Bernabé, Casas y cementerios islámicos, p. 580.

En síntesis, aquellos datos pueden revelar una cierta presión demográfica entre finales del siglo XII y la primera mitad del XIII, de forma que sería factible suponer una relación entre el final de la dominación almohade

\footnotetext{
${ }^{49}$ P. Jiménez, J. Navarro, Casas y tiendas, pp. 498-504. Lo más importante es que en la casa 4 se documentó una planta alta que se cree que debía estar en el ángulo SO de la vivienda arrancando del propio zaguán y montando sobre dos estructuras de ladrillo localizadas en ese mismo extremo del patio (pp. 513-519).
} 
y una profunda reducción de viviendas, ya que es muy difícil constatar la proliferación de hábitats domésticos tan fragmentados antes de la segunda mitad del siglo $\mathrm{XII}^{50}$. De un tiempo acá, una plausible respuesta al crecimiento demográfico en época almohade ha sido dada por las aportaciones norteafricanas pero, sobre todo, gracias a los flujos migratorios del norte ${ }^{51}$. De hecho, la hipótesis aquí planteada no entra en conflicto con aquella, aunque aquí se defiende un flujo más acentuado y se identifican además sus causas. ¿Con qué otros datos podemos contar para poder demostrar ese aspecto? Cercanos estudios sobre demografía en la Murcia del siglo XIII proponen una población de entre 24.000 y 25.000 habitantes en la ciudad frente a los 13.000 del siglo $\mathrm{XI}^{52}$. Estos resultados proceden del cálculo que combina la superficie de la ciudad -descontando algunos lugares comunes- con la de la mediana de las viviendas. La paradoja es que, aportando una tasa de crecimiento más o menos reconocida para la Edad Media del $2 \%$, los 24.000 ó 25.000 habitantes de la ciudad no armonizan, ya que se obtendría una cifra de unos 19.500 individuos a mediados del siglo XIII, lo que deja claro que entre el siglo XI y el XIII hubo una significativa aportación demográfica ${ }^{53}$. Con todo, el desconocimiento real de la superficie de la ciudad entre los siglos XI y XIII hace que cualquier propuesta sobre población tenga que considerarse con mucha precaución, pues los recientes hallazgos bajo el jardín de San Esteban han puesto de relieve una ciudad mucho más saturada allí donde se creía una trama urbana menos densa $^{54}$.

Lo arriba planteado invita a una lectura donde no resulta satisfactorio un aumento de la densidad de la población y la consiguiente fragmentación de su parcelario por un natural crecimiento demográfico sino por una apor-

${ }^{50} \mathrm{Si}$ se observa un establecimiento típico anterior a esta fecha como el asentamiento de Baŷȳāna-Pechina, se observa que la superficie de todas las viviendas no descendía de los $100 \mathrm{~m}^{2}$ (salvo excepcionalmente la vivienda 1, de $44,25 \mathrm{~m}^{2}$ ). Así está el caso de la vivienda 2, de $131 \mathrm{~m}^{2}$; la vivienda 3 , de $119 \mathrm{~m}^{2}$; y, la vivienda 4 , de 124,28 $\mathrm{m}^{2}$. Los excavadores de este yacimiento fecharon su construcción en la primera mitad del siglo X. Véase: F. Castillo, R. Martínez, La vivienda hispano-musulmana, pp. 111-127.

${ }^{51}$ Quien expone más claramente la posibilidad de flujos migratorios desde el Norte es R. Azuar, Campesinos fortificados, pp. 229-238. También J. Torro plantea la cuestión desde un punto de vista de agrupamiento de aljamas en Fortificaciones en Yibal Balansiya, pp. 385-418.

${ }^{52}$ A. Almagro, Planimetría de las ciudades, pp. 421-448 y J. Manzano, Notas sobre demografía, pp. 117-181. Los 13.000 habitantes fueron calculados por J.A. Ramírez, J.A. Martínez, Introducción al urbanismo, p. 569 (nota 19).

${ }^{53}$ Sobre la tasa de crecimiento ver el trabajo de J. García, La inmigración Norte-Sur, pp. 187 y ss. Para una idea general sobre el proceso demográfico en la península Ibérica en el siglo XIII puede verse el trabajo de A. Barrios, A. Martín, Demografía medieval, passim.

${ }^{54}$ Lo cierto es que la zona empieza a urbanizarse en el siglo XI para lograr una fuerte densidad entre la segunda mitad del siglo XII y la del XIII. Véase:A.Robles, J.A. Sánchez, E. Navarro, Arquitectura residencial andalusí, pp. 205-219. 
tación inmigratoria considerable, que pudo llegar a representar un $22 \%$ del total del siglo XIII. Una explicación para entender la enorme partición de las viviendas durante aquel siglo -cuando se crearon pequeños habitáculos de escasos metros cuadrados-, sería la ya descrita movilidad social, basada en la concentración en las ciudades y alquerías provistas de torres-refugio. Ahora bien, ¿cómo podría haberse articulado un asentamiento de refugiados en una ciudad y en un entorno como el de Murcia y, lo más importante, con qué mecanismos podría haber contado la ciudad para hacer efectivo tal asentamiento? ¿Cómo insertar a un grupo de refugiados, de unidades familiares ajenas a los grupos clánicos nativos, en un paisaje social relativamente armónico? Nuevamente las fuentes ofrecen una interesante respuesta al enfatizar el papel de la aljama como organización comunal en las ciudades andalusíes a la hora de tomar graves decisiones. Los ejemplos abundan tras la muerte de Ibn Hūd al-Mutawakkil; y el Llibre dels Feyts muestra el papel mancomunal de los más notables o viejos -a través de la jassa- durante la campaña de 1265-1266 en seis ocasiones, una de ellas en el cerco de la ciudad de Murcia ${ }^{55}$. Al acudir a la aljama o a aquellos aparentes poderes públicos de la ciudad, resulta inevitable tener presente el trabajo de Ch. Mazzoli-Guintard cuando pone el acento en el papel de sus habitantes para gestionar los problemas in extremis ${ }^{56}$. Y también hay que tener presente las aportaciones de C. Trillo San José sobre la composición de las alquerías cuando llama la atención sobre el papel decisorio de la aljama, donde incluso podían despuntar individuos carismáticos con efecto mediador o gestor ${ }^{57}$. Esto conduce nuevamente a los poderes fugaces elevados tras 1228 y también a los individuos singulares como Muhammad al-Gālib, sobornado para lograr la rendición de Elche ${ }^{58}$. En el caso de la ciudad de Murcia, la lectura del Llibre dels Feyts pone de relieve que, aún siendo al-Wātiq su emir, la aljama fue la que tomó las más graves decisiones, tanto la entrega de la ciudad como la partición de la misma ${ }^{59}$. Y esa capacidad en la distribución de la propiedad -aún en un caso forzado- es importantísima puesto que

\footnotetext{
${ }^{55}$ Además, la conducta de los diferentes interlocutores del rey Jaime deja claro que entre una entrevista y otra debió haber debate en el seno de la aljama. Los casos son: en Bíar, Villena, Elda, Petrer y Elche (capítulos 410-418). En Murcia más aún: "E ells grayren nos la paraula que nos los deyem, mas dixeren que nons podien respondre menys de conseyl daquels de la vila" (cap. 434); más adelante aclara quienes componían el consejo "e ells responeren nos que hauien haut lur acort ab los ueyls de la ciutat" o más claramente aún "e dixeren nos que la paraula que nos los hauiem mostrada que la hauien mostrada als ueyls e als sauis homens de la vil" (cap. 439). En M. Aguiló (ed.), Chronica o comentaris.

${ }^{56}$ Ch. Mazzoli-Guintard, Des pouvoirs, pp. 129-152.

${ }^{57}$ C. Trillo, La alquería y su territorio, pp. 243-262; idem, ¿:Podemos saber cómo funcionaban, pp. 279-298. Sobre la cuestión ver también P. Guichard, Quelques reflexions, pp. 7-20.

${ }^{58}$ M. Aguiló (ed.), Chronica o comentaris, cap. 417.

${ }^{59}$ Ibidem, caps. 445 y ss.
} 
conduce inevitablemente a preguntarse por la noción de propiedad y hasta qué extremo podía la comunidad disponer de ella. De hecho, gracias a los trabajos de C. Trillo San José en el ámbito de las alquerías, se sabe de la existencia de diferentes tipos de propiedad de la tierra sometida a evolución; que había terrenos incultos de los que una persona podía convertirse en propietario por vivificación; que había tierras comunales que podían ser expropiadas por el estado; y que se podía ejercer la compraventa de propiedades ${ }^{60}$. En el ámbito de la ciudad, ¿por qué no suponer la existencia de terrenos comunales -o solares, si se acepta al tratarse de la ciudad-baldíos, aprehendidos y habitados, expropiados y habitados, etc. a la manera de las alquerías? Y en un paisaje urbano de debilitamiento de los lazos clánicos y en una situación de presión demográfica, ya no sólo aquellas fórmulas de urbanización sino también -a la vista de las decisiones de la aljama en cuanto a la repartición de la ciudad de Murcia- de disponer de manera más o menos coercitiva de toda la edilicia doméstica de la madīna ${ }^{61}$.

\subsection{La parcelación y concentración de la propiedad de la tierra en la huerta}

Del mismo modo que en las viviendas de la ciudad de Murcia se ha detectado una fortísima parcelación, el estudio del dominio de la tierra de la huerta circundante y del disfrute de sus rentas a partir del texto del Repartimiento revela datos de aproximada coincidencia con aquel factor.

Cuando al principio de este trabajo hacíamos referencia a la necesidad de dotar de un contexto adecuado al fenómeno de las revueltas urbanas del siglo XIII, poniendo énfasis en la relación con sus aledaños, introducíamos la huerta como factor a tener en cuenta; sobre todo, en relación a su propiedad y producción, teniendo a la alquería como unidad básica de organización. En Murcia, la alquería era la célula básica en el entramado de la sociedad y de la economía de la huerta, cuyo origen se tiende a remontar al mismo momento del asentamiento árabe y a la consiguiente fundación de la ciudad de Murcia. Su complejidad radicaba en su estructura, que en la lectura del texto del Repartimiento se compone de heredades, bienes habices, rahales, reales, etc., elementos que no serían sino una muestra del tipo de sociedad que los creó, ya que su variedad demostraría diferentes funciones en el paisaje periurbano ${ }^{62}$.

\footnotetext{
${ }^{60} \mathrm{C}$. Trillo, ¿Podemos saber cómo funcionaban, pp. 252 y ss.

${ }^{61}$ Ibidem, p. 287 y ss. También véase: J.A. Martínez, J.A. Ramírez, Murcia, una ciudad del siglo XI, pp. 57-75.

${ }^{62} \mathrm{~J}$. Torres Fontes (ed.), Repartimiento de Murcia, passim.
} 
Por su naturaleza, las alquerías agrupaban a miembros y clientes de un mismo clan del que tomaban el nombre ${ }^{63}$. En el panorama de una huerta, en cuyo epicentro se ubicaba una dinámica ciudad, las alquerías estaban fuertemente ligadas a ella por un flujo comercial, fiscal, etc., lo que, como es natural, estaba en relación con ciertos factores de producción como su abastecimiento hídrico (figs. 7 y 8).

Acequias y artefactos de aprovechamiento del agua servían a los propósitos de un importante sector de la población huertana, que se hallaba dispersa en función del asentamiento inicial. Es evidente, sin embargo, que el paso del tiempo provocó que esa distribución no fuera constante ni uniforme, influyendo en la disposición interna de sus elementos y en la preponderancia de unas alquerías sobre otras. En este sentido, se infiere que la acequia recibía en un tramo el nombre de la alquería bien porque la tierra explotada, el poblamiento de ella, el radio de influencia de sus infraestructuras o todo ello a la vez se encontraba dispuesto a lo largo de la misma. El Repartimiento, por ejemplo, se refiere a la alquería de Barreras -que denomina de Benibarrira, cuya extensión era de 700 tahúllas de regadío- que, a su vez, daba nombre al tramo de la acequia mayor meridional que pasaba por sus tierras; por su parte, esta acequia y algunas subsidiarias regaban propiedades de la alquería de Tell Alquibir y de las vecinas de Tell Alçaguer, Benieça, etc. ${ }^{64}$. Pues bien, el texto del Repartimiento hace mención expresa a la influencia de la alquería de Barreras sobre dos de ellas mediante un hecho social tan trascendente como una mezquita: et ademas que a la mezquita mayor de Benibarrira viene los moros de Tel Alquibir et de Benieça a oracion cada viernes. Como, según aquella fuente, existía también una torre adscrita a aquella alquería de Barreras parece evidente que, además, protegía a los pobladores de aquellas otras dos alquerías, poniendo de manifiesto, en consecuencia, una cierta hegemonía estructural de Barreras sobre las otras (fig. 9) ${ }^{65}$. Más aún, su último propietario antes del Repartimiento fue el sayyid Abū Zayd, quien ostentó su dominio en régimen de iqtāa' por concesión del emir de Murcia, Muḥammad b. Hūd Baḥā' al-Dawla ${ }^{66}$.

\footnotetext{
${ }^{63}$ Sobre esta cuestión, remito nuevamente a los trabajos de C. Trillo, La alquería y su territorio, pp. 243-262; idem, ¿Podemos saber cómo funcionaban? pp. 279-298.

${ }^{64}$ La tahúlla es la unidad de medida de origen musulmán de uso todavía en la huerta de Murcia, cuya extensión equivale a 1.117,96 m²/0,11 ha.

${ }^{65} \mathrm{~J}$. Torres Fontes (ed.), Repartimiento de Murcia, pp. 213-214. Parece ser que la torre de Barreras debió actuar como eje defensivo de numerosas alquerías como las cercanas Tell Alquibir (actual pedanía de Era Alta, de 700 tahúllas) y Benieça (de 700 th.). En total, esta torre pudo dar protección a un ámbito de 1.400 tahúllas o 154 ha. Los datos provienen en su mayor parte del estudio realizado por J. Torres Fontes, Repartimiento y Repoblación, pp. 70 y 165-166.

${ }^{66} \mathrm{P}$. Guichard, Al-Andalus frente a la conquista, pp. 313-314.
} 


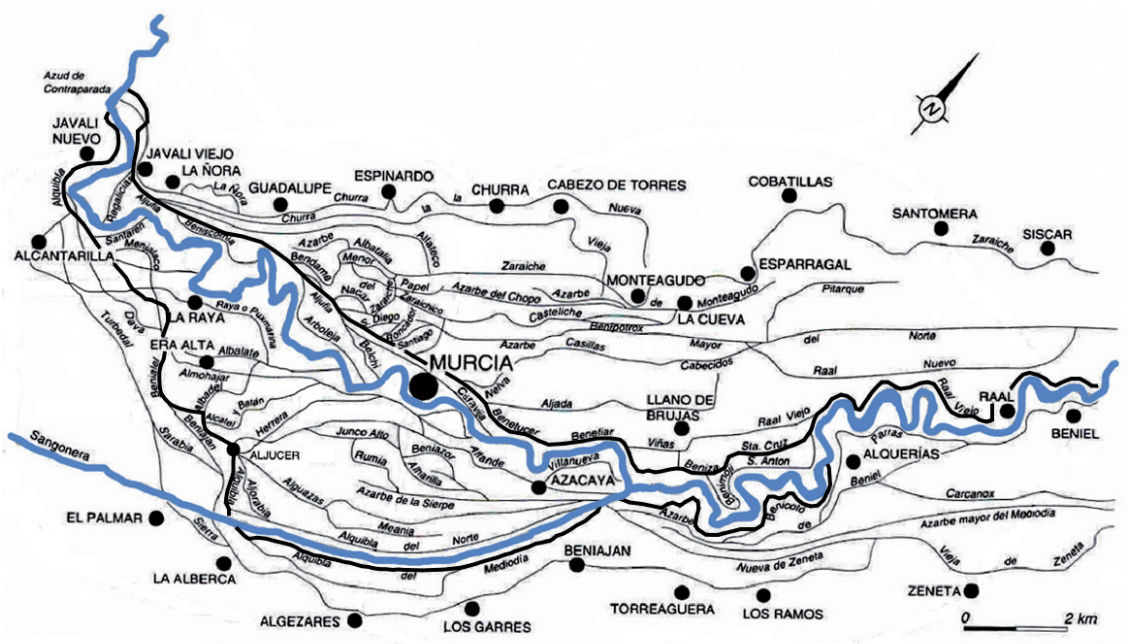

Fig. 7. Croquis de la huerta de Murcia en la actualidad con sus pedanías y acequias. En trazo más grueso el río y las dos acequias mayores. Fuente: J. Manzano, Aproximación a la estructura.

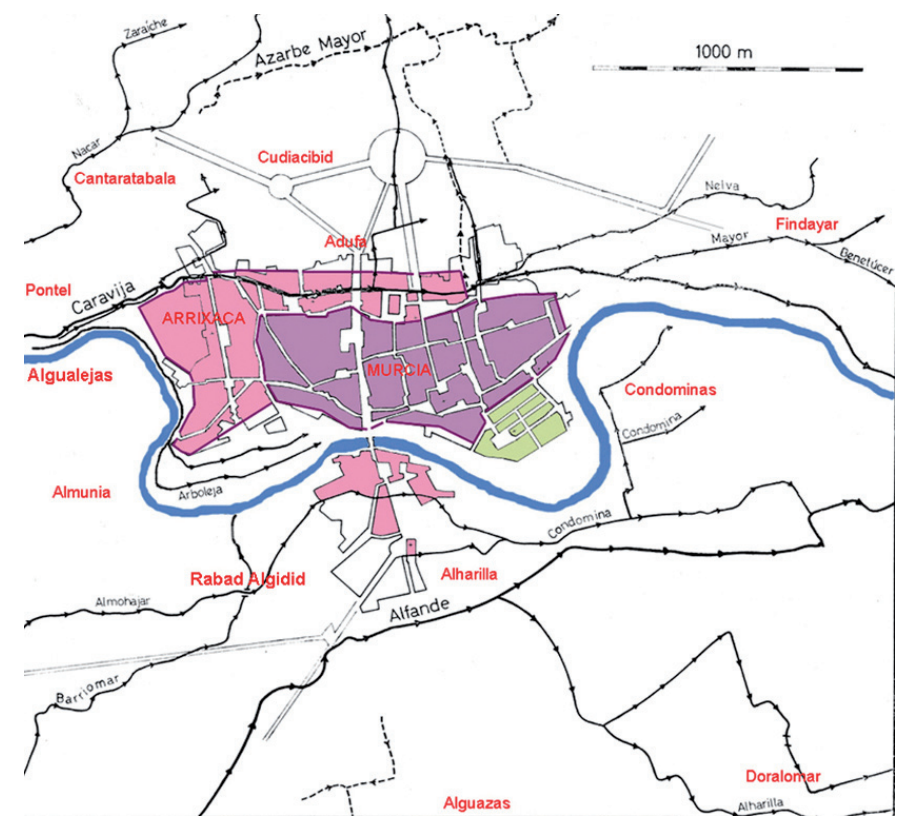

Fig. 8. Croquis de la ciudad de Murcia y de su entorno entre los siglos XII y XIII, donde figuran tanto las alquerías que circundaban la ciudad como la red de acequias que les daba agua. 


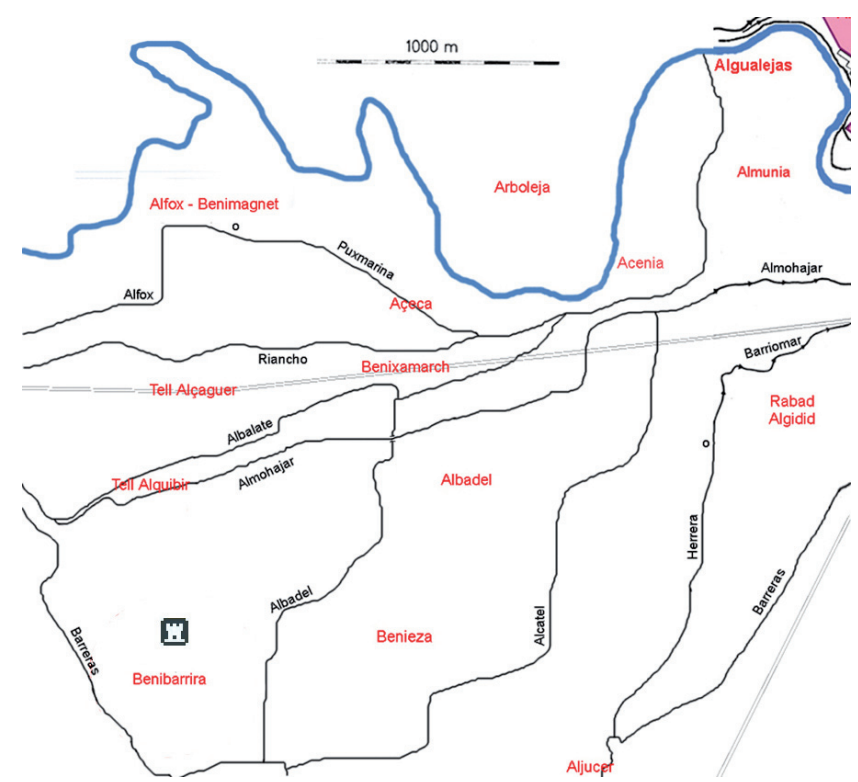

Fig. 9. Croquis de localización de la alquería de Barreras y sus vecinas, situadas todas al suroeste de la ciudad de Murcia. Se advierte el nombre de la localización de las alquerías y el trazo de las acequias de que servían agua.

Advertido lo anterior, ¿en qué situación se encontraba la huerta de Murcia en la primera mitad del siglo XIII? De entre los escasos estudios sobre ésta, uno de ellos pone de relieve cómo, con el paso de los siglos, la tenencia en las alquerías fue evolucionando del sistema de propiedad tribal para pasar a estar caracterizada por fórmulas de hegemonía de unos individuos sobre otros: es el análisis del Repartimiento que realizó J. Manzano Martínez referido a los propietarios desalojados entre los años 1272 y $1273^{67}$. Este trabajo demostraba un tipo de alquería cuyo parcelario estaba muy fragmentado, existiendo, a la vez, potentes concentraciones de tierra en manos de unos pocos individuos cuyo origen familiar prácticamente nada tenía que ver con los gentilicios que identificaban a las alquerías. En líneas generales, del conjunto de las seis alquerías pudo observar un $15 \%$ de propietarios con explotaciones superiores a una hectárea (más de nueve tahúllas), que reunían el 50\% del total de las tierras; en el otro extremo, un grupo de huertanos mayoritario (el 50\%)

${ }^{67}$ Las alquerías estudiadas provenían del texto de la quinta partición de la huerta de Murcia: Albadel (67,40\% de su total); Aljucer (50,70\%); Benabía (47,25\%); Beniaján Algarbía (100\%); Benihuadah (65\%) y Rabad Algidid (27'65\%). Véase J. Manzano, Aproximación a la estructura, pp. 61-75. La fuente es J. Torres Fontes, Repartimiento de Murcia, pp. 159-246. 
que no llegaba a poseer el $15 \%$ del total de las propiedades y donde la superficie de ellas no sobrepasaba las 3 tahúllas; el resto de propietarios (el 35\%) poseía el $35 \%$ de las propiedades de las alquerías (tabla 3 ).

Tabla 3. Proporción de propiedad en la huerta de Murcia en el siglo XIII

\begin{tabular}{|l|l|r|}
\hline TRAMOS (TAHÚLLAS) & $\%$ PROPIETARIOS & $\%$ TIERRAS \\
\hline $0,10-1,50$ & $25,00 \%$ & $5,00 \%$ \\
$1,51-3,00$ & $25,00 \%$ & $10,00 \%$ \\
$3,01-6,75$ & $25,00 \%$ & $25,00 \%$ \\
$6,76-9,00$ & $10,00 \%$ & $10,00 \%$ \\
+9 tahúllas $(1 \mathrm{Ha})$ & $15,00 \%$ & $50,00 \%$ \\
TOTAL & $100 \%$ & $100 \%$ \\
\hline
\end{tabular}

Fuente: J. Manzano, Aproximación a la estructura, pp. 61-75.

Observó, además, que había campesinos que poseían la propiedad fragmentada, como el caso de Çaad Achameni, dueño de 4 tahúllas en Aljucer repartidas en tres parcelas o de Çaet Aben Çaet -posiblemente el sayyid Abū Zayd- quien tenía 14,7 tahúllas distribuidas en cinco parcelas ${ }^{68}$. Y, finalmente, casos en que uno o dos individuos llegaban a concentrar una importante cantidad de tierra y de rentas; incluso una familia, los Banū Waḍḍāh, que eran propietarios del $25 \%$ de la tierra de la alquería de Benihuadah (58,86 tahúllas) y del $31,62 \%$ de sus rentas (26,36 alfabas) sin que sobresaliera ninguna otra familia $(\text { tabla } 4)^{69}$.

${ }^{68}$ Ibidem, p. 70.

${ }^{69} \mathrm{La}$ alfaba es una medida de valor que se repite en el proceso de conquista y colonización del reino de Murcia durante todo el siglo XIII. Su significado es impreciso, pero vendría a estar relacionado con el caudal de agua que correspondía a cierto espacio de tierra relacionada con la correspondiente dotación de las acequias. Según J. Torres Fontes, Repartimiento y Repoblación, pp. 53-65, no se trataría de una medida de superficie sino un valor que se atribuye a tierra de regadío y de secano, con el sentido de valor catastral, con el objeto de dar una estimación a la renta. Sobre este tema véase J. Manzano, Antroponímia gentilicia, p. 202-203 y 209-210; P. Díaz Cassou, Ordenanzas y costumbres, p. 18. 
Tabla 4. Porcentaje de propietarios y disfrute de rentas en alquerías de la huerta de Murcia en el siglo XIII

\begin{tabular}{|l|l|l|l|}
\hline ALQUERÍA & FAMILIA & TAHULLAS & ALFABAS \\
\hline \multirow{5}{*}{ Benabía } & Alhandafi $(6,25 \%$ del censo) & $15,12(9,45 \%)$ & $10,95(11,21 \%)$ \\
\cline { 2 - 4 } & Almayorqui & $5(3,12 \%)$ & $4,32(4,42 \%)$ \\
\cline { 2 - 4 } & Almazlana & $5,61(3,49 \%)$ & $5,65(5,78 \%)$ \\
\cline { 2 - 4 } & Alponti & $7,24(4,52 \%)$ & $5,17(5,29 \%)$ \\
\cline { 2 - 4 } & Epónimo & 3 & $2,31(2 \%)$ \\
\hline \multirow{5}{*}{ Beniaján Algarbía } & Alpatiti & $23,72(7,90 \%)$ & $9,35(7,59 \%)$ \\
\cline { 2 - 4 } & Banu Çayd & $25,07(8,35 \%)$ & $9,07(7,36 \%)$ \\
\cline { 2 - 4 } & Farach & $21,49(7,16 \%)$ & $7,43(6,03 \%)$ \\
\cline { 2 - 4 } & Epónimo & & $3 \%$ \\
\hline Benihuadah & Banu Waddah & $58,86(25 \%)$ & $26,36(31,62 \%)$ \\
\hline
\end{tabular}

Fuente: J. Manzano, Antroponimia gentilicia, pp. 206-208.

Datos aportados con posterioridad a aquel estudio han servido para afianzar el planteamiento propuesto, a partir de la relación de una tercera parte (!) de las rentas permutadas a la Orden de San Juan en los años noventa del siglo XIII; una fecha próxima al último repartimiento, que mostraba una cierta conservación del régimen hacendístico anterior a la conquista, como demuestran sus largas listas de censatarios ${ }^{70}$. Las alquerías objeto de estudio -Bani Huraite, Alferce, Algualeja y Findaxar- localizadas en el heredamiento de la Aljufía, en el área correspondiente a la tercera partición de la huerta realizada entre los años 1266 y 1267, revelaron datos muy aproximados en cuanto a concentraciones de rentas en manos de una o dos familias. En el primer grupo -Bani Huraite, Alferce y Algualeja-, entre sus miembros se pudo observar al menos un parentesco afín -el de los Banū Jalaf- que agrupaba el 9\% del conjunto de las rentas (8,98 alfabas); familia, por cierto, localizada como propietaria en la alquería de Beniaján Algarbía a través de Mahomat aben Jalaf ${ }^{71}$. Destacaba además la presencia de Abu Abdille aben Hotab, con un 4\% de las rentas enajenadas (3,67 alfabas), miembro de los Banū Jatțāb, reconocida familia aristocrática de la Murcia previa a la conquista castellana, cuyo pariente fue emir durante seis meses en 1239 y también poseedor de tierras en la alquería de Beniaján Algarbía ${ }^{72}$. Por su parte, en la otra alquería -Fidaxa-, se obser-

\footnotetext{
${ }^{70}$ A.V. Frey-Sánchez, La estructura de la propiedad, pp. 49-76.

${ }^{71}$ J. Manzano, Antroponímia gentilicia, pp. 210-211.

${ }^{72}$ Ibidem, pp. 210-213.
} 
vó a dos linajes muy representativos: los Banū Tubit, con una concentración del 5\% del total de las rentas enajenadas (4,18 alfabas); y los Banū al-Qarraq, con el $4 \%$ de las rentas enajenadas (4,15 alfabas).

Observando en conjunto las rentas del anterior estudio y del que antecede a estas líneas, pueden advertirse datos interesantes respecto a la distribución de la tierra y de sus rentas en la huerta de Murcia a mediados del siglo XIII. Así, en el caso de las alquerías sanjuanistas, se apreciaba que, en el primer grupo, el 61,9\% de los censatarios tenían una renta inferior a la media y el $38,1 \%$ superior, destacando además que sólo cinco superaban en 2/3 la media y, de éstos, solo uno podría calificarse como verdaderamente opulento; en Fidaxat ocurría algo parecido pues, de 36 propietarios, 22 no alcanzaban la media, dándose casos (11) en que la renta acaso superaba una alfaba. Algo similar se comprueba al comparar estos datos con los de J. Manzano Martínez: así, en la alquería de Benabía, se observa que, de los 62 campesinos censados, el $61,3 \%$ no llegaba a la media de las rentas, mientras que el 38,7\% sí lo hacía; de ellos, además, sólo 7 individuos superaban en 2/3 la renta media de la alquería, dos de los cuales pertenecían a las dos familias que más tahúllas reunían. En la alquería de Beniaján Algarbía, los datos indican que, de todo el conjunto, sólo el $21,3 \%$ de los censados superaba la media de las rentas descritas mientras que el 78,7\% no; del conjunto, como en la anterior alquería, sólo siete superaban en $2 / 3$ la media; además, de entre ellos, una familia y un individuo solo agrupaban un gran número de tahúllas. Por su parte, en la alquería de Benihuadah fueron tomados los siguiente valores: $76,7 \%$ que no superaba la media de la alquería y $23,3 \%$ que sí, registrándose cinco censados que superaban en $2 / 3$ la renta y que pertenecían a la familia dominante cuyo epónimo -recuérdese- daba nombre a la alquería.

Teniendo presente que los datos referidos no suponen el total de los censos que constituían las diferentes alquerías -salvo en el caso de de Beniaján Algarbía-, y que, en el segundo grupo, corresponden a un tercio de las rentas totales, todos estos números permiten, no obstante, advertir que tanto la propiedad como la producción de la tierra de la huerta de Murcia parecían estar fuertemente fraccionadas y, en ocasiones, distribuidas en grandes propiedades cuyo parcelario se hallaba disperso. Sin disponer de una referencia precedente, resulta muy interesante advertir una proporción muy similar de la propiedad de la tierra y el disfrute de sus rentas en el sultanato de Granada a finales del siglo $\mathrm{XV}^{73}$. En todo caso, no queda del todo claro el origen de tanta fragmentación ni la inserción de individuos ajenos al conglomerado clánico

${ }^{73}$ C. Trillo, ¿Podemos saber cómo funcionaban? pp. 290 y ss. También es de interés el estudio de E. Molina, M.C. Jiménez, La propiedad de la tierra en la vega, pp. 449-459.

ANUARIO DE Estudios MEdievales, 44/2, julio-diciembre 2014, pp. 845-884

ISSN 0066-5061, doi:10.3989/aem.2014.44.2.06 
de la alquería, teniendo presente además las complejas resistencias familiares puestas de relieve por C. Trillo para conjurar la pérdida de patrimonio. Atrás en el tiempo, los clanes habían concentrado grandes extensiones de tierra y, como consecuencia última de la segmentación social -el proceso social descrito por P. Guichard-, se observa cómo, en ocasiones, la mayoría de las propiedades y rentas se llegó a acumular en individuos pertenecientes a linajes cuyo epónimo nada tenía que ver con el topónimo de la alquería estudiada ${ }^{74}$. En síntesis, lo que llama la atención es la magnitud de las desigualdades entre los propietarios de tierra en el seno de una alquería, diferenciándose pequeñas y grandes parcelas, modestos y acaudalados censatarios en unas cifras cuya horquilla iría desde el $85 \%$ al $75 \%$ y desde el $15 \%$ al $25 \%$ respectivamente. También resulta significativo observar la absoluta ausencia de relaciones familiares entre la gran mayoría de los propietarios o censatarios. En último término, este fenómeno podría representar el predominio de minifundios cuyos dueños, como propietarios reales o como clientes o aparceros de otras familias de la alquería, de otra o de la ciudad, podrían ser simples huertanos o habitantes de Murcia. De una forma u otra, lo cierto es que ya no se observa la organización de tipo clánico que en su momento había podido articular el dominio de la tierra y la distribución de sus riquezas. Así que, rota aquella homogeneidad, cabe preguntarse por las consecuencias más allá de la tenencia de la tierra, por ejemplo, la forma en que era gobernada la alquería y, lo que es más importante, por quién. Porque si el común de la alquería no tenía una relación familiar que la estructurase está claro que conviene replantearse el papel de las formas tribales de decisión en común, esto es, la aljama. Aquella desestructuración, la aparición de importantes apellidos urbanos que poseían significativas cantidades de tierra y el poderoso papel determinante de la ciudad en el caso de su capitulación -y de su huerta- llevan inevitablemente a preguntarse si el papel decisorio de las alquerías estaba sometido o, al menos, determinado por la acción de personajes y/o familias de la oligarquía urbana. Un posible ejemplo de influencia vendría de la mano del emir de Murcia, Muḥammad b. Hūd Bahāa' al-Dawla, cuando otorgó el dominio de la alquería de Barreras al sayyid Abū Zayd en régimen de iqță en los años del protectorado castellano. Que este individuo y su familia poseyeran dominios en otras alquerías de la huerta (Aljucer y Beniaján Algarbía) o que otros linajes como los Banū Jalaf, los Banū Ṭāhir o los Banū Jaț̣āb aparecieran aquí y allá en los censos del Repartimiento permite consolidar la idea del paisaje huertano que se está defendiendo. En definitiva, en un ambiente de grandes y peque-

${ }^{74}$ J. Manzano, Antroponímia gentilicia, p. 212. Sobre el proceso social llamo la atención sobre el trabajo de P. Guichard, Evolución sociopolítica, pp. 53-74.

ANUARIO DE Estudios MEDIEVALES, 44/2, julio-diciembre 2014, pp. 845-884

ISSN 0066-5061, doi:10.3989/aem.2014.44.2.06 
ños propietarios, resulta evidente que existieron posibilidades de producirse fenómenos de desigualdad social por muchas variables tales como la productividad de las tierras, el acceso al agua, el comercio de sus productos, etc. Es casi imposible saber cuándo se desvencijó la organización clánica de la huerta de Murcia: en este trabajo defendemos la hipótesis de que, en su mayor medida, sucediese tardíamente como consecuencia de las emigraciones desde las zonas menos seguras y de las conquistadas, tal y como pone de relieve la existencia del gentilicio al-Mayorqui en una de las alquerías estudiadas. De una forma o de otra, lo cierto es que en el siglo XIII unos pocos poseían una gran cantidad de recursos dominicales; o, lo que es lo mismo, existía en Murcia a principios del siglo XIII una serie de linajes terratenientes de importante influencia económica y social.

\section{SÍNTESIS Y CONCLUSIONES. UNA HIPÓTESIS SOBRE LA SOCIEDAD Y PODER POLÍTICO EN LAS CIUDADES DE AL-ANDALUS EN EL SIGLO XIII A TRAVÉS DEL EJEMPLO DE MURCIA.}

En el siglo XIV, Ibn Jaldūn hizo un sencillo y elocuente análisis de lo sucedido en al-Andalus durante el siglo anterior:

Existe (...) una disposición que induce a los hombres a vincularse unos con otros y reunirse en grupos, aún cuando no pertenezcan a la misma estirpe (...) En una ciudad, buena parte de los habitantes se ligan entre sí (...) Cuando el reino (...) cae en decadencia (...) los habitantes de las ciudades (...) sienten la necesidad de un gobierno capaz de dirigirlos y de protegerlos. Entonces acuden al recurso de instituir un consejo administrativo, el cual establece al instante la línea de demarcación entre los hombres de alto rango y los de la clase inferior, pues todos los hombres aspiran naturalmente al dominio y el mando; por lo tanto, los miembros del consejo al ver la ciudad fuera de la autoridad del sultán y del poder del reino, todos ellos pretenden apoderarse de la dirección. En la lucha que surge, cada uno se apoya en un grupo de partidarios compuesto de sus clientes, de sus amigos y sus afiliados; prodiga incluso su dinero entre la gente del pueblo, a fin de reunirlos en torno a su causa. El que de entre esos jefes logra vencer a sus rivales los persigue y los hostiga hasta que los haya matado o expulsado de la ciudad ${ }^{75}$.

De este modo, el célebre cronista hacía una profunda reflexión sobre la naturaleza de la práctica desaparición de al-Andalus, poniendo de relieve

\footnotetext{
${ }^{75}$ Ibn Jaldūn, Al-Muqaddimah, p. 666.
} 
una estructura vertical en los sucesos políticos del siglo XIII. Lo que describió fue, por decirlo claro, unos movimientos por el poder llevados a cabo por linajes andalusíes en sus principales ciudades; hecho éste sobre el que hemos llamado la atención desde el inicio de este trabajo, mostrando cómo fue un proceso inicialmente protagonizado por los propios almohades, para luego ser adoptado en sus formas por los andalusíes.

Al principio de este trabajo se invitaba a descubrir nuevos factores en las causas de las revueltas urbanas y la sucesión de poderes políticos en las ciudades de al-Andalus, haciendo hincapié en la importancia de la presencia de los linajes implicados y su origen. Es fundamental llamar la atención sobre este aspecto porque algunas fuentes ofrecen indicios suficientes como para afirmar su supervivencia durante la dominación almohade, manteniendo una serie de privilegios que serían con el tiempo el fundamento de su capacidad de reacción ${ }^{76}$. ¿A qué tipo de privilegios se podría hacer referencia? Para responder a esta pregunta resulta imprescindible reparar en la estrecha relación entre numerosos linajes y funcionarios de al-Andalus y el imperio almohade durante la segunda mitad del siglo XII y el primer cuarto del XIII; hecho éste perfectamente evidente si leemos la crónica de al-Șalāt. Ejemplo de ello son los Banū Mardan̄̄š y la influencia acumulada durante el emirato de su pariente Muhammad b. Sacad. Registros toponímicos de fuentes posteriores ponen de manifiesto hasta qué extremo se llegó a dotar a esa y otras familias de un importante peculio a través de concesiones territoriales tales como las iqta $\bar{a}^{c}$, convirtiéndolos además en propietarios de un buen número de bienes de producción ${ }^{77}$. Y naturalmente esta disponibilidad de tierras, molinos o incluso de ciertos edificios públicos y obviamente de arrendatarios que los mantuvieran sería posible debido a dos hechos íntimamente relacionados y a los que hemos hecho referencia más atrás: por un lado, la desintegración de la sociedad tribal y, por otro, la subsiguiente alteración de los bienes de producción y del mismo proceso productivo. Los datos más relevantes para explicar la desarticulación del sistema tribal han demostrado que, en la antroponimia gentilicia de la huerta de Murcia, se registraba una escasa supervivencia del antropónimo que denominaba a la alquería: sólo un $10 \%$ del total de sus pobladores en el mejor

\footnotetext{
${ }^{76}$ Ibn Sāḥib al-Ṣalāt, Al-Mann bil-Imāma: [La presencia del califa almohade al-Mu'minīn en Murcia] "En ese [mes] mandó que se presentasen Hilāl b. Mardanı̄s y sus hermanos y su tío AbūlHaŷŷâŷy Yūsuf en su sesión noble; los trató amablemente y les mostró su satisfacción, justicia y generosidad; y les hizo con esto todo lo bueno fácil, y le prometió de su público y de su secreto lo que no lo alcanzó con al-Ma'mūn al-Ḥasan b. Sahl”.' (p. 225).

${ }_{77}$ De hecho, la presencia del sayyid Abū Zayd como "señor" de la alquería de Tell Alquivir y del $r a$ '̄̄s de Orihuela Abū Ŷa'far b. 'Îșām como propietario de un rahal en la huerta de Murcia no podían indicar sino la faceta terrateniente de ambos mandatarios.
} 
de los $\operatorname{casos}^{78}$. Al citar el caso de al-Mayorqui, es muy posible que pudiera deberse a un factor exógeno, probablemente a las migraciones de población procedente de lugares conquistados por castellanos y aragoneses como Toledo y el valle del Ebro, que, por otra parte, se intensificaron conforme avanzaba el siglo XIII. De este modo tendría sentido el otro gran factor desencadenante de las revueltas urbanas: debido a la necesidad de cobijar a estos pobladores, tanto los importantes linajes -valiéndose de las seculares fórmulas de clientelismo o de contratos- como la aljama los asentó en alquerías, contribuyendo así a la fragmentación de la propiedad, al desarrollo del derecho de la propiedad individual frente a la colectiva y, finalmente, en función de la productividad, permitiendo la definitiva consolidación de estamentos frente a los clanes.

En ese escenario propuesto -descrito, por otra parte, por Ibn Jaldūncomo una forma de asegurar el dominio del estado sobre una sociedad tribal, la política decisión almohade de permitir a las familias aristocráticas andalusíes tener aquella privilegiada relación de propiedad de la tierra debió asegurar el mantenimiento de un constante flujo de rentas proveniente, a su vez, de los clientes, aparceros y los famosos exaricos de las fuentes cristianas ${ }^{79}$. Con este panorama podría comprenderse la supervivencia de algunos linajes tales como los Banū Jaț̣āb, Banū Mardanīš, Banū Waḍ̣āḥ, Banū Huḍayr, etc., y sus posibilidades de acaparar para sí el poder de una localidad como último intento para asegurar la resistencia frente a la conquista por Castilla o Aragón. Por todo ello, puede considerarse plausible la hipótesis de que estas familias tuvieran una proyección social y económica suficiente como para hacer frente a un poder político central débil o, en otro extremo, a una aljama dividida y manipulable. Hay, no obstante, sustanciales diferencias respecto a lo que podríamos caracterizar como un comportamiento feudal en sentido estricto; y la más importante de ellas es su ámbito de influencia, que estaba bastante bien definido por el tipo de sociedad urbana en que estaba enmarcada la civilización andalusí; de ahí que fuera, por ejemplo, Lorca el lugar desde donde Muhammad b. 'Alī b. Aḥlà se batiera contra los Banū Hūd ${ }^{80}$. Sólo de este modo se comprende tanto la sublevación de Muhammad b. Yūsuf b. Hūd en

\footnotetext{
${ }^{78}$ J. Manzano, Antroponímia gentilicia,pp. 201-218.

${ }^{79} \mathrm{Ibn}$ Jaldūn, Al-Muqadimmah. Resulta reveladora la reflexión realizada para explicar la crisis del siglo XIII en al-Andalus: "Para apoderarse del poder, no tuvo necesidad sino de un pequeño partido, los Rouasá (raíces o jefes) [sic]. En efecto, no tenía menester de una numerosa assabiya porque tal espíritu de solidaridad apenas existía en aquel ámbito, pues allí ya no había más que soberano y súbditos (...) pues al iniciar su carrera tenía cierto partido y si bien bastante pequeño, era suficiente para la ejecución de sus planes. De hecho, el espíritu de agnación y de tribu era bien escaso en España" (p. 340).

${ }^{80}$ Conviene tener presente las reflexiones sobre las ciudades y sus zonas de influencia que ha hecho Ch. Mazzoli-Guintard en Los territorios urbanos, pp. 15-24.
} 
las cercanías de Murcia en 1228 y la rápida captura de esta ciudad apoyado por una gran parte de la aristocracia murciana como también la inmediata adhesión de casi la totalidad de las localidades de al-Andalus; rápida adhesión a Ibn Hūd al-Mutawakkil, en fin, que tuvo su reverso en una también rápida segregación de los diferentes poderes locales desde sus respectivas ciudades como sucedió desde 1232 hasta su definitiva conquista.

\section{BIBLIOGRAFÍA CITADA}

Aguiló y Fuster, Marian (ed.), Chronica o comentaris del gloriosssim e invictissim Rey en Jacme primer, Rey Darago, de Mallorques e de Valencia, Compte de Barcelona e de Montpesler..., Barcelona, Llibreria d'Alvar Verdaguer, 1873. (Biblioteca Virtual Joan Lluís Vives, Historiografia a la Corona d'Aragó:

http//www.lluisvives.com/servlet/SirveObras/jlv/12937178668079308 532624/index.htm [consulta: 13/04/2012]).

Al-Ḥimyarī, Kitāb al-Rawd al-mictạrr, Lévi-Provençal, Évariste (ed.), La Péninsule Ibérique au Moyen Âge d'après le Kitab al-Rawd al-Mitar d'Ibn ${ }^{c}$ Abd al-Muncim al-Himyari, Leiden, E. J. Brill, 1938.

Almagro Gorbea, Antonio, Planimetría de las ciudades hispanomusulmanas, "al-Qanțara" 8 (1987), pp. 421-448.

Arié, Rachel, España musulmana (siglos VIII-XV), t. III de la Historia de España dirigida por M. Tuñón de Lara, Barcelona, Labor, 1982.

Azuar Ruiz, Rafael, Campesinos fortificados frente a los conquistadores feudales en Ferrandes Ferreira, Isabel Cristina (ed.), Mil Anos de fortificações na Península Ibérica e no Magreb (500-1500), Actas do Simposio Internacional sobre Castelos, Lisboa, Ediçiones Colibrí, 2004, pp. 229-238.

Barrios García, Ángel; Martín Expósito, Alberto, Demografía medieval: modelos de poblamiento en la Extremadura castellana a mediados del siglo XIII, "Studia historica. Historia medieval" 1 (1983), pp. 113-148.

Bazzana, André, Maisons d'al-Andalus. Habitat médiéval et structures du peuplement dans l'Espagne orientale, II vols. Madrid, Casa de Velázquez, 1992.

Benito i Monclús, Pere, Fams i caresties a la Mediterrània occidental durant la baixa edat mitjana. El debat sobre "la crisi de la crisi", "Recerques" 49 (2004), pp. 179-194.

Bernabé Guillamón, Mariano, Informe preliminar sobre el Solar de la Calle Raimundo de los Reyes, 5-7, de Murcia, "Memorias de Arqueología" 9 (1995), pp. 517-521. 
Bernabé Guillamón, Mariano, Casas y cementerios islámicos en Murcia. El solar $n^{\circ} 1-3$ de la plaza de Santa Eulalia, "Memorias de Arqueología" 10 (1996), pp. 574-594.

Bernabé Guillamón, Mariano; López Martínez, José Domingo, El Palacio Islámico de la calle Fuensanta. Murcia, Murcia, Museo de Murcia, 1993.

Boloix Gallardo, Bárbara, De la Taifa de Arjona al Reino Nazarí de Granada (1232-1246): en torno a los orígenes de un estado y de una dinastía, Jaén, Instituto de Estudios Giennenses, 2006.

Bradley, Raymond S.; Briffa, Keith R.; Cole, Julia; Hughes, Malcom K.; Osborn, Timothy J., The climate of the last millennium en Alverson, Kevin; Bradley, Raymond S.; Pedersen, T.F. (eds.), Paleoclimate, Global Change and the Future, Berlin, Springer-Verlag, 2003. pp. 105-141.

Castillo Galdeano, Francisco; Martínez Madrid, Rafael, La vivienda hispano-musulmana en Baŷȳāna-Pechina (Almería), en Bermúdez López, Jesús; Bazzana, André (coords.), La casa hispano-musulmana. Aportaciones de la arqueología, Granada, Patronato de la Alhambra y Generalife, 1990, pp. 111-127.

De las Cagigas López de Tejada, Isidoro, Los mudéjares, II, Madrid, Instituto de Estudios Africanos, 1949.

De las Cagigas López de Tejada, Isidoro, Sevilla almohade y los últimos años de su vida musulmana, Madrid, CSIC,1951.

Diaz Cassou, Pedro, Ordenanzas y costumbres de la Huerta de Murcia. Madrid, Fortanet, 1889.

Fierro Bello, María Isabel, Doctrinas y movimientos de tipo mesiánico en al-Andalus, en De la Iglesia Duarte, José Ignacio (coord.), Milenarismos y Milenaristas en la Europa Medieval. IX Semana de Estudios Medievales, Logroño, Instituto de Estudios Riojanos, 1999. pp. 159-176.

Fierro, Bello María Isabel, Le mahdi Ibn Tûmart et al-Andalus, l'élaboration de la légitimité almohade, "Revue des mondes musulman et de la Méditerranée" 91-94 (2000), pp 107-124.

Frey-Sánchez, Antonio Vicente, La estructura de la propiedad de la tierra en Murcia durante la conquista castellana, "Estudios de Historia de España" 9 (2007), pp. 49-76.

García Latorre, Juan, La inmigración Norte-Sur y el "pecado original" de la demografía española, en Pimentel Siles, Manuel (coord.), Mediterráneo económico, procesos migratorios, economía y personas, $\mathrm{Al}-$ mería, Ediciones Cajamar, 2002, pp. 175-200.

García-Bellido y García, Javier, Principios y reglas morfogenéticas de la ciudad islámica, "Qurțuba. Estudios andalusíes" 2 (1997), pp. 59-86. 
González González, Julio, Las conquistas de Fernando III en Andalucía, "Hispania" 25 (1946), pp. 515-631.

González González, Julio, Población en la nueva tierra, en Jover Zamora, José María (coord.), Historia de España. Vol. XIII-1: La expansión peninsular y mediterránea (c. 1212 - 1350). La Corona de Castilla, Madrid, Espasa-Calpe, 1990, pp. 76-77.

Goosse, H.; Arzel, O.; Luterbacher, J.; Mann, M. E.; Renssen, H.; Riedwyl, N.; Timmermann, A.; Xoplaki, E.; Wanner, H., The origin of the European "Medieval Warm Period, "Climate of the Past" 2 (2006), pp. 99-113.

Guichard, Pierre, Evolución sociopolítica de la región murciana durante la época musulmana, "Cuadernos de Historia de España" 10 (1983). pp. 53-74.

Guichard, Pierre, Les musulmans de Valence et la reconquête (XIè-XIIIè siècles), Damasco, Institut français de Damas, 1991, II vols. Edición castellana: Al-Andalus frente a la conquista cristiana. Los musulmanes de Valencia (siglos XI-XIII), Valencia, Universidad de Valencia, 2001.

Guichard, Pierre, Quelques réflexions sur la societé urbaine en Al-Andalus, "Mainake" 25 (2003), pp. 7-20.

Huici Miranda, Ambrosio, Historia política del imperio almohade, I, Tetuán, Instituto General Franco de Estudios e Investigación Hispano-Árabe, 1947.

Ibn 'Id̄ārī, Kitāb al-Bayān al-Mugrib, I, Huici Miranda, Ambrosio (ed.), Tetuán, Instituto General Franco de Estudios e Investigación HispanoÁrabe, 1953.

Ibn 'Id̄ārī, Kitāb al-Bayān al-Mugrib, II, Huici Miranda, Ambrosio (ed.), Tetuán, Instituto General Franco de Estudios e Investigación HispanoÁrabe, 1954.

Ibn Abī Zarc', Rawd al-Qirțās, en Carmona González, Alfonso, El Reino de Murcia entre 1238 y 1275 en las fuentes árabes de los siglos XIII y XIV, "Yakka. Revista de Estudios Yeclanos" 5 (1994), pp. 53-62.

Ibn Abī Zarc, Rawd al-Qirțās, Huici Miranda, Ambrosio (ed.), Valencia, Anubar Ediciones, 1964.

Ibn al-Abbār, al-Hulla al-siyarā', en Carmona González, Alfonso, Textos árabes acerca del reino de Murcia entre 1243 y 1275. Aspectos jurídicos y políticos, "Glossae. Revista de Historia del Derecho europeo" 5-6 (1993-1994), pp. 243-253.

Ibn Jaldūn, Kitāab al-'Ibar, en McGuckin De Slane, William (ed.), Histoire des Berbéres et des dynasties musulmanes de l'Afrique septentrionale, Argel, 1852-1856. 
Ibn Jaldūn, al-Muqaddimah, en Feres, Juan; Trabulse, Elías (eds.), Introducción a la Historia Universal, Méjico, Fondo de Cultura Económica, 1977.

Ibn Șāḥib al-Ṣalāt, Al-Mann bi-l-Imāma, Huici Miranda, Ambrosio (ed.), Tetuán, Editora Marroquí, 1965.

Idris, Hady Roger, Contribution à l'étude de la vie économique en Occident musulman médiéval, "Revue de 1'Occident Musulman et Méditerranéen" 15-16 (1973), pp. 75-87.

Jiménez Castillo, Pedro; Navarro Palazón, Julio, Platería 14. Sobre cuatro casas andalusíes y su evolución (siglos X-XIII), Murcia, Ayuntamiento de Murcia, 1997.

Jiménez Castillo, Pedro; Navarro Palazón, Julio, Casas y tiendas en la Murcia andalusí. Excavación en el solar municipal de la plaza de Belluga, "Memorias de Arqueología" 10 (2002), pp. 489-532.

Jiménez Castillo, Pedro; Navarro Palazón, Julio, Un ejemplo de saturación del parcelario andalusí: la excavación del solar de la calle Organistas de Murcia, "Memorias de Arqueología" 15 (2010), pp. 781-802.

Laliena Corbera, Carlos, Licencias para la exportación de cereal de Aragón y Cataluña a mediados del siglo XIII, "Aragón en la Edad Media" 20 (2008), pp. 445-456.

Lamb, Hubert Horace, The early Medieval warm epoch and its sequel, "Palaeogeography, Palaeoclimatology, Palaeoecology" 1 (1965), pp. 13-37.

López Martínez, José Domingo; Sánchez Pravia, Juan Antonio, Excavación arqueológica de urgencia en solar sito entre las calles Trapería 3638, Andrés Baquero y callejón de Los Peligros, en Iniesta Sanmartín, Ángel (ed.), Actas de las VIII Jornadas de Arqueología Regional. Murcia, Editora Regional, 1997, pp. 60-62.

Manzano Martínez, José, Memoria preliminar de los trabajos realizados en el subsuelo de la actual plaza de Europa (antiguo Garaje Villar). Ciudad de Murcia, "Memorias de Arqueología" 3 (19871988), pp. 354-396.

Manzano Martínez, José, Antroponimia gentilicia y genérica en la Huerta de Murcia, "Verdolay. Revista del Museo Arqueológico Provincial de Murcia" 5 (1993), pp. 201-218.

Manzano Martínez, José, Aproximación a la estructura de la propiedad musulmana de la tierra en la Huerta de Murcia (siglo XIII) en "Castrum" 5, Madrid, Casa de Velázquez - Murcia, Ayuntamiento de Murcia, 1995, pp. 61-75.

Manzano Martínez, José, Notas sobre demografía islámica en Murcia (siglos XII-XIII), "Miscelánea Medieval Murciana" 25-26 (2001-2002), pp. 117-181. 
Martínez Enamorado, Virgilio, Algunas reflexiones en torno al fin del almohadismo. El siglo XIII en el Islam de Occidente, en I Jornades de Recerca Històrica de Menorca. La Manūrqa de Sa'īd ibn Hakam, un país islàmic a Occident, "Publicacions des Borns" 15-16 (2006) pp. 11-28.

Martínez López, José Antonio; Ramírez Águila, Juan Antonio, Murcia, una ciudad del siglo XI, "Verdolay. Revista del Museo Arqueológico Provincial de Murcia" 8 (1996), pp. 57-75.

Mazzoli-Guintard, Christine, Des pouvoirs dans les villes d'al-Andalus du pouvoir politique aux intentions citadines (IVe/Xe-IXe/XVe siècles), "Al-Andalus-Magreb: estudios árabes e islámicos" 10 (20022003), pp. 129-152.

Mazzoli-Guintard, Christine, Los territorios urbanos de las ciudades andalusies: perspectivas de estudio, en Martínez Enamorado, Virgilio (ed.), I Congreso Internacional Escenarios urbanos de al-Andalus y el Occidente musulmán, Málaga, 2011, pp. 15-41.

Menant, François, Crisis de subsistencia y crisis agrarias en la Edad Media: algunas reflexiones previas, en Oliva Herrer, Hipólito Rafael; Benito i Monclús, Pere (eds.), Crisis de subsistencia y crisis agrarias en la Edad Media, Sevilla, Universidad de Sevilla, 2007, pp. 17-60.

Menéndez Pidal, Ramón (ed.), Primera Crónica General, Madrid, Gredos, 1955.

Molina López, Emilio, Aziz b. Jattab, destacada personalidad política, científica y literaria murciana del siglo XIII, "Miscelánea Medieval Murciana" 4 (1978), pp. 63-86.

Molina López, Emilio, El Levante y Almería en el marco de la política interior del emir murciano Ibn Hūd al-Mutawakkil (1236 - 1238), "Awrāq" 2 (1978), pp. 55-63.

Molina López, Emilio, De nuevo sobre el reconocimiento público del poder político. La adhesión 'abbasí en al-Andalus (siglo XIII) en Homenaje al Profesor José María Fórneas Besteiro, II, Granada, Universidad de Granada, 1994, pp. 793-812.

Molina López, Emilio; Jiménez Mata, María del Carmen, La propiedad de la tierra en la vega de Granada a finales del siglo XV. El caso de Alitaje, "Anaquel de Estudios Árabes" 12 (2001), pp. 449-479.

Munuera, David; Martínez López, José Antonio, Por tierra de castillos. Guía de las fortificaciones medievales de la región de Murcia y rutas por sus antiguos caminos, Murcia, Ediciones Tres Fronteras, 2010.

Muñoz López, Francisco, Sobre la evolución de una manzana de casas andalusies en Murcia, "Memorias de Arqueología" 8 (1994), pp. 416-436. 
Navarro Palazón, Julio, La casa andalusí en Siyâsa: ensayo de una clasificación tipológica, en Bermúdez López, Jesús; Bazzana, André (coords.), La casa hispano-musulmana. Aportaciones de la arqueología, Granada, Patronato de la Alhambra y Generalife, 1990, pp. 177-198.

Navarro Palazón, Julio (coord.), Una casa islámica en Murcia. Estudio de su ajuar (siglo XIII), Murcia, Ayuntamiento de Murcia, 1991.

Navarro Palazón, Julio, Un palacio protonazari en la Murcia del siglo XIII: al-Qāsr al-Saguīr, en Navarro Palazón, Julio (ed.), Casas y Palacios de al-Andalus. Siglos XII-XIII, Madrid, El Legado Andalusí, 1995, pp. 177-206.

Navarro Palazón, Julio; Jiménez Castillo, Pedro, Estudio sobre once casas de Siyâsa, "Memorias de Arqueología" 5 (1990), pp. 525-595.

Navarro Palazón, Julio; Jiménez Castillo, Pedro, Plantas altas en edificios andalusies. La aportación de la arqueología , "Arqueología Medieval" 1 (1996), pp. 107-137.

Ramírez Águila, Juan Antonio; Martínez López, Juan Antonio, Introducción al urbanismo de la Murcia islámica a través de una intervención de urgencia en los solares número 31, 33 y 35 de la Calle Platería (Junio - Octubre, 1994), "Memorias de Arqueología" 9 (1995), pp. 548-569.

Robles Fernández, Alfonso; Sánchez Pravía, Juan Antonio; Navarro Santa Cruz, Elvira, Arquitectura residencial andalusí y jardines en el arrabal de la Arrixaca. Breve síntesis de las excavaciones arqueológicas realizadas en el jardín de San Esteban, Murcia (2009), "Verdolay. Revista del Museo Arqueológico Provincial de Murcia" 13 (2011), pp. 205-219.

Rodríguez Llopis, Miguel, Señoríos y feudalismo en el Reino de Murcia. Murcia, Universidad de Murcia, 1984.

Sánchez Martínez, Manuel, Guerra, avituallamiento del ejército y carestías en la Corona de Aragón: la provisión de cereal para la expedición granadina de Alfonso el Benigno (1329-1333), "Historia. Instituciones. Documentos" 20 (1993), pp. 523-549.

Stothers, Richard B., Climatic and demographic consequences of the massive volcanic eruption of 1258, "Climatic Change" 45 (2000), pp. 361-374.

Torres Fontes, Juan (ed.), Repartimiento de Murcia, Murcia, Real Academia Alfonso X El Sabio, 1971.

Torres Fontes, Juan, Repartimiento y Repoblación en la huerta de Murcia, Murcia, Real Academia Alfonso X El Sabio - Universidad de Murcia, 1991.

Torró i Abad, Josep, Fortificaciones en Yibal Balansiya. Una propuesta de secuencia, en Malpica Cuello, Antonio (coord.), Castillos y territorio en Al-Andalus, Granada, Athos - Pérgamos, 1998, pp. 385-418.

ANUARIO DE Estudios MEdievales, 44/2, julio-diciembre 2014, pp. 845-884

ISSN 0066-5061, doi:10.3989/aem.2014.44.2.06 
Trillo San José, Carmen, ¿Podemos saber cómo funcionaban las alquerías "por dentro"? Un planteamiento sobre la organización económica y social en el ámbito rural de al-Andalus, "Revista d'Història Medieval" 12 (2001-2002), pp. 279-298.

Trillo San José, Carmen, La alquería y su territorio en Al-Andalus: estrategias sociales de organización y conservación, “Arqueología Espacial" 26 (2006), pp. 243-262.

Vega Martín, Miguel; Peña Martín, Salvador; Feria García, Manuel, El mensaje de las monedas almohades. Numismática, traducción y pensamiento islámico, Cuenca, Feria Editorial - Universidad de Castilla La Mancha, 2002.

Vernet, Robert, Recherches sur la production et la circulation des céréales dans le Maghreb médiéval, "Revue d'Histoire et de Civilisation du Maghreb" 13 (1976), pp. 31-62.

Vernet, Robert, La production céréalière dans le Maghreb du XIIIè siecle, en $X$ Congreso de Historia de la Corona de Aragón, Vol. III: Jaime I y su época, Zaragoza, Institución Fernando el Católico (CSIC), 1980, pp. 253-268.

Vidal Castro, Francisco, Frontera, genealogía y religión en la gestación y nacimiento del reino nazarí de Granada. En torno a Ibn al-Ahmar, en Toro Ceballos, Francisco; Rodríguez Molina, José (coords.), III Estudios de Frontera. Convivencia, defensa y comunicación en la Frontera, Jaén, Diputación de Jaén, 2000, pp. 793-810.

Vidal Castro, Francisco, Política, instituciones, espacio y economía, en Viguera Molins, María Jesús (coord.), El reino nazarí de Granada (1232-1492), vol. VIII-3 de la Historia de España dirigida por Ramón Menéndez Pidal, Madrid, Espasa-Calpe, 2002, pp. 47-248.

Viguera Molins, María Jesús, Historia política, en Viguera Molins, María Jesús (coord.), El retroceso territorial de al-Andalus. Almorávides y almohades. Siglos XI al XIII, vol. VIII-2 de la Historia de España dirigida por Ramón Menéndez Pidal, Madrid, Espasa-Calpe, 1997, pp. 39-143.

Fecha de recepción: octubre 2012

Fecha de aceptación y versión final: abril 2013 